\title{
Flow Field and Scalar Measurements in a Series of Turbulent Partially-Premixed Dimethyl Ether/Air Jet Flames
}

\author{
Bruno Coriton ${ }^{1}$, Seong-Kyun Im $^{2}$, Mirko Gamba ${ }^{3}$ and Jonathan H. Frank, ${ }^{1, *}$ \\ ${ }^{1}$ Combustion Research Facility, Sandia National Laboratories, Livermore, CA 94551, USA \\ ${ }^{2}$ Dept. of Aerospace and Mechanical Engineering, University of Notre Dame, Notre Dame, IN 46556. \\ USA \\ ${ }^{3}$ Dept. of Aerospace Engineering, University of Michigan, Ann Arbor, MI 48109. USA
}

Full-length article,

Submitted to Combustion and Flame on November 3, 2016

* Corresponding Author:

Jonathan H. Frank

P.O. Box 969, MS. 9053

Livermore, CA 94551, USA

Fax: (925) 294-2595

jhfrank@sandia.gov 


\title{
Flow Field and Scalar Measurements in a Series of Turbulent Partially-Premixed Dimethyl Ether/Air Jet Flames
}

\author{
Bruno Coriton ${ }^{1}$, Seong-Kyun Im $^{2}$, Mirko Gamba ${ }^{3}$ and Jonathan H. Frank ${ }^{1, *}$
}

We present a series of benchmark flames consisting of six partially-premixed piloted dimethyl ether (DME)/air jet flames. These flames provide an opportunity to understand turbulence-flame interactions for oxygenated fuels and to develop predictive models for these interactions using a canonical burner geometry. The development of accurate models for DME/air flames would establish a foundation for studies of more complex oxygenated fuels. The flames are stabilized on a piloted jet burner similar to that of the partially-premixed methane/air jet flames that have been studied extensively within the context of the TNF Workshop. This series of six jet flames spans jet exit Reynolds numbers, $R e_{D}$, from 29,300 to 73,300 and stoichiometric mixture fractions, $\xi_{s t}$, from 0.35 to 0.60 . Flame conditions range from very low probability of localized extinction to a high probability of localized extinction and subsequent re-ignition. Measurements in the flames are compared at downstream locations from 5 to 25 diameters above the nozzle exit. Mean and fluctuating velocity components are measured using stereo particle image velocimetry (SPIV). Simultaneous laser-induced fluorescence (LIF) imaging of $\mathrm{OH}$ and $\mathrm{CH}_{2} \mathrm{O}$ provides insights into the distribution of these intermediate species in partiallypremixed DME/air flames. OH LIF imaging is also combined with SPIV to investigate the strain rate field across the reaction zone.

Keywords: DME, Turbulent Jet Flames, PIV, $\mathrm{OH}$ LIF, $\mathrm{CH}_{2} \mathrm{O}$ LIF, TNF workshop. 


\section{Introduction}

Dimethyl ether (DME) is a promising clean alternative fuel for use in ground transportation compression ignition (CI) engines [1-3]. DME's high cetane number and easy vaporization also make it a potential fuel candidate for homogeneous charge compression ignition (HCCI) engines [2]. DMEfueled engines have the potential of significantly reduced $\mathrm{CO}$ and soot emission levels because of the presence of oxygen and the absence of a carbon-carbon bond in the DME molecule $\left(\mathrm{CH}_{3}-\mathrm{O}-\mathrm{CH}_{3}\right)$ [4, 5]. DME can be produced from conversion of biomass, natural gas and coal [1]. Despite the potential of DME as a clean fuel, appropriate combustion technologies must be developed and a fundamental understanding of the interplay between DME chemistry and turbulence is required.

Turbulent jet flames provide a canonical geometry in which to study turbulence-flame interactions and have been used in the development and testing of turbulent combustion models. Within the context of the International Workshop on Measurements and Computation of Turbulent Flames (TNF) [6], the series of piloted methane/air jet flames (Sandia flames $C$-to- $F$ ) spanning Reynolds number of approximately 13,400 to 44,800 have been used extensively for experimental studies [7-10] and model development [11-15]. DME flames represent a step forward in chemical complexity and are a good starting point for studying turbulent combustion of oxygenated fuels since DME is the simplest ether [16-19]. The progression of turbulent combustion studies from methane to DME combustion not only provides insights into turbulence-chemistry interactions for an oxygenated fuel but also may reveal enhanced effects of turbulent transport for intermediate species relative to methane flames.

Detailed chemical-kinetic reaction mechanisms for DME/air combustion are available: Fischer/Kaiser et al., 2000 [20, 21] consisting of 78 species and 351 reactions, Zhao et al., 2008 [22] employing 55 species and 290 reactions. These mechanisms have been tested over a range of conditions using experimental data on ignition delay times, flame speeds, and flame species [21, 23-30]. However, there remain significant discrepancies in predictions of combustion intermediates such as formaldehyde, which plays a central role in the decomposition of DME [31, 32]. In turbulent flames, combustion intermediates can be subject to significant transport by turbulent mixing.

In the present paper, we establish a series of piloted partially-premixed DME/air jet flames that are analogous to the well-studied Sandia $\mathrm{CH}_{4} /$ air jet flame series. The DME/air jet flames have increasing levels of localized extinction and Reynolds numbers from 29,300 to 73,300. The maximum Reynolds number of the DME/air jet flame series is approximately $60 \%$ larger than the $\mathrm{CH}_{4} /$ air jet flames. The main DME/air jet flame series has an air-to-fuel ratio of 4:1 (by vol.), which results in the same stoichiometric mixture fraction of 0.35 as the $3: 1$ air-to-fuel ratio of the $\mathrm{CH}_{4} /$ air flames. In addition, we 
consider DME/air jet flames with larger air-to-fuel ratios of 6:1 and 8:1 that represent a progression toward premixed combustion. The mean location of the reaction zone in these flames is positioned in a different region of the jet shear layer closer to the jet axis as a result of the larger stoichiometric mixture fraction.

\section{Experimental Methods}

\subsection{Piloted Jet Burner and Experimental Conditions}

Experiments were performed on a series of six piloted partially-premixed DME/air jet flames (photographs displayed in Fig. 1) with jet exit Reynolds numbers, $R e_{D}$, and stoichiometric mixture fractions, $\xi_{s t}$, as listed in Table 1. For the series of flames labelled $D_{41}, E_{41}, F_{41}$ and $G_{41}$, characterized by a constant air-to-DME volume ratio of 4-to- 1 corresponding to $\xi_{s t}=0.35$, the jet flow rate progressively increased from $120 \mathrm{LPM}$ to $300 \mathrm{LPM}$, resulting in $R e_{D}$ of approximately $29,300,44,000$, 58,600 , and 73,300. The total volumetric flow rates of the jet flows in Flames $D$ to $F$ are the same for the DME/air and CH4/air jet flame series [8]. The flames labelled $F_{41}, F_{61}$ and $F_{81}$ had a constant jet flow rate of 240 LPM and a varying air-to-DME volume ratio of 4-to-1, 6-to-1 and 8-to-1, respectively, resulting in increasing $\xi_{s t}$ values of $0.35,0.48$ and 0.60 . The jet exit Reynolds numbers of the three $F$ flames were comparable with an approximately $10 \%$ decrease in $R e_{D}$ between flames $F_{41}$ and $F_{81}$ as a result of the change in composition (Table 1).

The piloted jet burner was a slightly revised version of the well-established Sydney burner configuration from the Sandia series of partially-premixed $\mathrm{CH}_{4} /$ air jet flames [8]. Specific dimensions were: a central jet diameter of $7.45 \mathrm{~mm}$ (as opposed to $7.2 \mathrm{~mm}$ in the Sandia $\mathrm{CH}_{4} /$ air Flame series), inner and outer diameters of the pilot annulus of $8.0 \mathrm{~mm}$ and $18.2 \mathrm{~mm}$, respectively, and a coflow diameter of $254 \mathrm{~mm}$. The pilot reactant mixture had an equivalence ratio of 0.6 and was composed of $\mathrm{C}_{2} \mathrm{H}_{2}, \mathrm{H}_{2}, \mathrm{CO}_{2}, \mathrm{~N}_{2}$ and $\mathrm{O}_{2}$ with the mole fractions listed in Table 2. The pilot and mean jet flow rates were scaled proportionally such that the energy release of the pilot is approximately $2 \%$ of the main jet for flames $D_{41}, E_{41}, F_{41}$ and $G_{41}, 2.9 \%$ for $F_{61}$ and $3.7 \%$ for $F_{81}$. These values were smaller than for the Sandia $\mathrm{CH}_{4} /$ air flames where the pilot energy release was approximately $6 \%$ of the main jet. The burner was surrounded by an air coflow with an initial velocity of $0.9 \mathrm{~m} / \mathrm{s}$ that was monitored using a hot-film anemometer. 
The gas flows to the jet and pilot were regulated using mass flow controllers, which were calibrated using piston-displacement calibration units (Sierra CalTrak) with an accuracy of $\pm 0.25 \%$. DME was supplied in pressurized liquid tanks preheated to $330 \mathrm{~K}$ to ensure a steady supply of gas. At ambient temperature and atmospheric pressure, DME is stable in the gas phase. Preheating of the DME tank did not affect the jet inlet temperature of $294 \mathrm{~K}$. Accurate positioning of the burner was controlled using a three-way motorized translation stage with a resolution of $<7 \mu \mathrm{m}$.

\subsection{OH LIF and $\mathrm{CH}_{2} \mathrm{O}$ LIF Imaging}

In one set of experiments, laser-induced fluorescence (LIF) imaging measurements of $\mathrm{OH}$ and $\mathrm{CH}_{2} \mathrm{O}$ were combined using the experimental configuration depicted in Fig. 2a. For OH-LIF excitation, the frequency doubled output of a Nd:YAG-pumped dye laser was tuned to the $\mathrm{Q}_{1}(6)$ transition $(\lambda=283.01 \mathrm{~nm}, 1.2 \mathrm{~mJ} /$ pulse $)$ of the $A^{2} \Sigma^{+} \leftarrow X^{2} \Pi^{+}\left(v^{\prime}=1, v^{\prime \prime}=0\right)$ band of $\mathrm{OH}$. A passive, single-cavity pulse stretcher was employed to lengthen the effective duration of the UV laser pulse. The longer laser pulse enabled the use of greater laser energy while operating in the linear LIF regime. The $\mathrm{OH}$ fluorescence emission from the $A-X(0,0)$ and $(1,1)$ bands were imaged onto an intensified CCD camera using a UV-camera lens (f.1. $=45 \mathrm{~mm}, \mathrm{f} / 1.8$ ) with color glass filters (UG11 and WG305) to block interferences, resulting in a projected pixel size of approximately $53 \mu \mathrm{m}$ and a field of view of $3.5 D \times 3.5 D$. The OH-LIF measurements were corrected for spatial variations in the average beam profile and the throughput of the imaging system. Shot-to-shot fluctuations were negligible for the subsection of the dye-laser beam that was used for LIF imaging. The OH-LIF signals were not corrected for local variations in quenching rates or the Boltzmann population fraction of the $\mathrm{OH}$ ground state.

As in Refs. [31-33], laser-induced fluorescence of formaldehyde was excited by the third harmonic of an injection seeded Nd:YAG laser (42 mJ/pulse) with a pulse stretcher similar to that of the OH-LIF system. The diode seed laser was temperature tuned to $\lambda=354.83 \mathrm{~nm}\left(\Delta \lambda \sim 0.003 \mathrm{~cm}^{-1}\right)$ to excite overlapping transitions in the $4_{0}^{1}$ band of the $\widetilde{\mathrm{A}}^{1} \mathrm{~A}_{2} \leftarrow \widetilde{\mathrm{X}}^{1} \mathrm{~A}_{1}$ system. In comparison to broadband excitation using the third harmonic output of an unseeded Nd:YAG laser [16, 34], narrowband excitation of formaldehyde resulted in higher fluorescence signal by a factor two [31] and reduced interferences from intermediate species [33]. The $\mathrm{CH}_{2} \mathrm{O}$ fluorescence emission was imaged onto an intensified CCD camera using a medium-format camera lens, an AR-coated singlet (f.1. $=-400 \mathrm{~mm}$ ), and a 35-mm format lens, resulting in a projected pixel size of approximately $19 \mu \mathrm{m}$ and a field of view of $2.5 D \times 2.5 D$. A color glass filter (GG375) in the imaging system blocked elastic scattering from the laser and transmitted the $\mathrm{CH}_{2} \mathrm{O}-\mathrm{LIF}$ signal. The laser beam was horizontally polarized to eliminate interference 
from Rayleigh or Raman scattering. The $\mathrm{CH}_{2} \mathrm{O}$-LIF measurements were corrected for the average variation in the laser beam profile and the throughput of the imaging system. For these corrections, response images were obtained by filling the field of view with a uniform stream of methane and recording the average $\mathrm{C}-\mathrm{H}$ stretch Raman scattering signal from the UV laser beam. A half-wave plate at $355 \mathrm{~nm}$ was used to rotate the polarization of the laser beam to vertical in order to maximize the Raman scattering signal without affecting the laser beam profile.

\subsection{Stereo Particle Image Velocimetry Measurements}

In a second set of experiments, OH LIF imaging was combined with velocity field measurements using the experimental configuration in Fig. 2b. Three-component velocity field measurements were performed using stereo particle image velocimetry (SPIV). The jet and coflow were seeded with $0.3 \mu \mathrm{m}$ aluminum oxide particles, which were illuminated by the second harmonic output $(\lambda=532 \mathrm{~nm})$ of a dual-head pulsed Nd:YAG laser. The laser beam was expanded by a factor of 2.5 in the vertical direction using a cylindrical telescope and formed into an approximately $1 \mathrm{~mm}$ thick sheet. A pair of CCD cameras (Cooke PCO, 1280 x 1024 px $^{2}$ ) equipped with Nikon 105-mm macro lenses were used to capture the particle scattering images. The cameras were mounted at 23 degrees with respect to the normal to the laser sheet. Imaging of particles in the laser-sheet plane was improved by the use of Scheimpflug mounts to compensate for tilting and shifting of the lenses with respect to the camera bodies. A narrow-bandwidth interference filter centered at $532 \mathrm{~nm}$ was placed in front of each camera lens to reduce interference from flame luminosity. The resulting field of view of the cameras was approximately $19 \times 14 \mathrm{~mm}^{2}$. The stereoscopic projections were calibrated using recordings of a dotarray target that was translated stepwise along the z-axis. This calibration was further improved using a self-calibration procedure based on a pinhole model [35], which resulted in a residual error of less than $0.2 \mathrm{px}$.

Velocity vector calculations for SPIV were performed using an iterative cross-correlation processing algorithm with dynamic windowing. After each processing pass, the size of the interrogation window was halved and offset by the displacement distance of the previous processing pass, which reduced the risk of correlation loss and provided finer spatial resolution. The aspect ratio of the interrogation windows was also iteratively elongated in regions of shear to improve the accuracy of the measurements [36]. The interrogation window size, $\Delta_{w}$, was reduced to a final nominal area of $32 \times 32 \mathrm{px}^{2}\left(474 \times 474 \mu \mathrm{m}^{2}\right)$ in flames $D_{41}, E_{41}$ and the $F$-flame series and an area of $48 \times 48 \mathrm{px}^{2}$ $\left(711 \times 711 \mu \mathrm{m}^{2}\right)$ in flame $G_{41}$ with $50 \%$ overlap between neighboring windows, which resulted in a 
vector spacing of $355 \mu \mathrm{m}$ in flame $G_{41}$ and $237 \mu \mathrm{m}$ in the other flames. The laser produced a pair of pulses at a repetition rate of $5 \mathrm{~Hz}$ with an inter-pulse time delay that varied from $3.0 \mu$ s to $8.1 \mu \mathrm{s}$. The pulse delay was adjusted for each flow condition to provide a maximum inter-frame particle displacement, $\Delta x_{p}$, between 8 and $24 \mathrm{px}$ depending on the measurement location. For the ensemble velocity statistics of Section 3.1, a universal outlier detection algorithm [37] was used to eliminate spurious vectors that were not replaced and therefore not included in the statistics. For the calculation of the conditional mean velocity gradients in Section 3.4, the spurious vectors were detected and replaced using the post-processing method of Garcia [38]. The $-3 \mathrm{~dB}$ cut-off frequency of the spatial filter was comparable to that of a two-pass top-hat filter with a kernel size of $\Delta_{w}$. The velocity fields were then interpolated onto the OH LIF images using 2D spline fitting.

\subsection{Accuracy of the Velocimetry Measurements}

The dominant sources of error and bias in the velocity measurements arose from the dynamic range and spatial resolution of the PIV imaging system. For standard two-component PIV measurements, the average error in the determination of particle displacements using dynamic windowing cross-correlation algorithms has been estimated to be as small as $0.04 \mathrm{px}$ by Westerweel et al. [39], but this estimation could be degraded by a factor of 2 to 3 in the presence of imaging noise and fluctuations in the particle image diameter and signal level [40-42]. In comparison, a stereoscopic imaging configuration with cameras angled at 46 degrees with respect to each other was estimated to reduce the error of the in-plane velocity components by $30 \%$ but yielded errors in the out-of-plane velocity that were approximately 2.3 times larger [43]. For SPIV measurements in the turbulent flames, the estimated uncertainties in determining particle displacements were $\Delta x_{p} \sim 0.08 \mathrm{px}$ for the in-plane velocity components and $\Delta x_{p} \sim 0.24 \mathrm{px}$ for the out-of-plane velocity component, which corresponded to velocities on the order of $0.003 U_{b u l k}$ and $0.01 U_{b u l k}$, respectively. In shear flows, velocity statistics could be biased in regions with small particle displacements $[36,44,45]$. The sensitivity of the ensemble velocity statistics to particle displacement was investigated by repeating the velocity measurements in flame $D_{41}$ at $x / D=5$ with a factor of two increase in the inter-pulse time, thereby doubling the maximum particle displacement from $12 \mathrm{px}$ to $24 \mathrm{px}$. The results showed no noticeable effect on the velocity statistics.

The spatial resolution of the SPIV measurements was limited by the size of the interrogation window, $\Delta_{w}$. Small-scale particle motions within an interrogation window introduced an additional source of measurement error [45, 46], and the presence of under-resolved turbulence lengthscales 
resulted in underestimates of velocity fluctuations $[47,48]$. The extent to which the SPIV measurements resolved the velocity field can be estimated by comparing the turbulence lengthscales with $\Delta_{w}$. For the turbulent flame conditions, the outer lengthscale, $\delta$, which is defined as the full width at half maximum (FWHM) of the radial profile of the mean axial velocity, varies from $\delta=7.5 \mathrm{~mm}$ for $x / D=5$ to $\delta=22.0 \mathrm{~mm}$ for $x / D=25$ (Section 3.1). Estimates of the Batchelor lengthscale, $\lambda_{B}$, using conventional scaling laws for non-reacting turbulent jets are in the range of $20 \mu \mathrm{m}$ to $50 \mu \mathrm{m}$ near the nozzle exit for the Reynolds numbers shown in Table 1 [49]. Although these values are relevant for the non-reacting air jets, the dissipative lengthscales in jet flames are larger than those of the corresponding non-reacting jets because of dilatation and increases in viscosity that result from the heat release. Using Rayleigh scattering imaging, Frank and Kaiser [50] found that the Batchelor lengthscales in the near-field of turbulent non-premixed jet flames were a factor of 2 to 3 larger than those in non-reacting jets of equivalent Reynolds numbers. Additionally, the dissipative lengthscales measured by Wang et al. [51] in the Sandia $\mathrm{CH}_{4}$-air flames $D\left(R e_{D}=22,400\right)$ and $E\left(R e_{D}=33,600\right)$ ranged between $65 \mu \mathrm{m}$ and $106 \mu \mathrm{m}$ for $x / D=7.5$-to-30. Using these results, we estimated that the Kolmogorov lengthscale, $\eta \approx \lambda_{B}$ for $S_{c} \approx 1$, in the reaction zone of the DME-air jet flames considered here ranged between $50 \mu \mathrm{m}$ and $100 \mu \mathrm{m}$, which was approximately 5-to-10 times smaller than $\Delta_{w}$ for flames $D_{41}, E_{41}$ and $F$ and 7-to-14 times smaller for flame $G_{41}$. Measurements of the finest scale turbulent velocity gradients with a bias of less than $10 \%$ would require a window size of less than $3 \eta[47,48,51]$. Given the resolution of the SPIV measurements, dissipative lengthscales could not be analyzed without significant bias. However, we were able to evaluate variations in the mean axial velocity across the reaction zone in Section 3.4. For all the flames, the shear layer thickness was between $3.5 \mathrm{~mm}$ and $5 \mathrm{~mm}$ at $x / D=5$ and increased with downstream location. Therefore, the lengthscales associated with the mean shear were significantly larger than $\Delta_{w}$, and these velocity gradient measurements were not significantly impaired by the SPIV spatial resolution.

\section{Results and Discussion}

Photographs of the chemiluminescence from the series of piloted jet flames are presented in Fig. 1. Burning conditions range from stable burning with small amounts of localized extinction in flame $D_{41}$ to less stable combustion with increased probabilities of extinction and intermittent flame ignition by the pilot gases in flames $F_{81}$ and $G_{41}$. The flames with constant stoichiometric mixture fraction, $D_{41}, E_{41}$, $F_{41}$ and $G_{41}$, have an average length of approximately 60 diameters, whereas the lengths of the flames 
$F_{61}$ and $F_{81}$ decrease to approximately $50 D$ and $40 D$, respectively. Flow field and scalar measurements are performed in the developing region of these jet flames for $x / D \leq 25$.

\subsection{Velocity Field Statistics}

The turbulent jet is a canonical configuration that has been studied extensively in non-reacting [5254] and reacting [7-17, 55-64] flows. The heat release in a jet flame introduces a decrease in gas density and an increase in viscosity that significantly reduce the entrainment rate of the coflow stream $[55,60]$. The rates of entrainment and mixing are important for modeling of turbulent jet flames and ultimately determine the flame height [59]. Velocity statistics are required to understand the effects of heat release on turbulent mixing as well as to validate numerical simulations and to determine boundary conditions. Conventional scaling laws typically apply in the far-field region of turbulent jets, but the effects of combustion in the near-field can have significant consequences on the downstream turbulence properties [58]. In this work, the flow fields are measured in the near-field for $x / D \leq 25$, which is a transitional region of turbulent jets where turbulence grows in the shear layer. Measurements in jet flames are compared to those in turbulent air jets with the same volumetric flow rates. In order to discern the effects of combustion of the DME/air jet mixture on the flow field, the air jet measurements are performed while using the corresponding pilot flames from the jet flames.

Radial profiles of the velocity fields in flame $D_{41}$ and the turbulent air jet $D_{\text {air }}$ are compared at axial locations of $x / D=5,10,15,20$ and 25 in Fig. 3. Although the flame and air jet have the same bulk exit velocity, $U_{b u l k}$, the mean axial velocity, $U$, exhibits a faster decay as a function of downstream location in the air jet than in the flame (Fig. 3a) because of the reduced entrainment rate in the flame. Between $x / D=5$ and 25 , the mean centerline velocity, $U_{o}$, decreases by $66 \%$ in the air jet and by only $22 \%$ in the flame.

The RMS of the axial velocity fluctuations, $u^{\prime}$, normalized by the bulk velocity is plotted for $D_{\text {air }}$ and $D_{41}$ in Fig. 3b. Turbulence initially develops inside the 7.45-mm diameter tube, resulting in a jet exit RMS velocity that is approximately $3.5 \%$ of the bulk velocity. Downstream of the nozzle, turbulence intensifies in the shear layer between the jet and coflow stream, as indicated by the off-axis peak in the profiles of $u^{\prime} / U_{\text {bulk }}$ at $x / D=5$ and 10 for both $D_{\text {air }}$ and $D_{41}$. Further downstream, for $x / D \geq 15$, the magnitude of the turbulent fluctuations in the non-reacting jet decays, indicating that the turbulent kinetic energy dissipates. The RMS axial velocity fluctuations along the jet centerline, $u_{0}^{\prime}$, initially increase more rapidly in the turbulent air jet than in the turbulent flame because of the larger entrainment rate of the coflowing air into the core of the non-reacting jet. For $x / D \geq 20$, the RMS axial 
velocity in $D_{\text {air }}$ peaks near the centerline and decreases monotonically with increasing radial position, suggesting that coflowing air is fully entrained into the core of the jet at these downstream locations. In the flame, the radial profiles of $u^{\prime} / U_{\text {bulk }}$ for $x / D \leq 25$ maintain an off-axis peak as a result of the lower entrainment rate, dilatation in the reaction zone, and fluctuations in the burning rate. In contrast to the air jet, the RMS axial velocity along the centerline of flame $D_{41}$ continues to increase as a function of downstream location attaining a value of $10 \%$ at $x / D=25$. The off-axis maximum value of $u^{\prime}$ is approximately $18 \%$ of $U_{b u l k}$ for $x / D \geq 15$ at a radial positon of $1.0 \leq r / D \leq 1.3$.

Profiles of the mean radial velocity component, $V_{\rho}$, normalized by the bulk velocity are plotted for $D_{a i r}$ and $D_{41}$ in Fig. 3c. The mean radial velocities are zero on the jet centerline and have peak positive values in the region of $r / D=0.5-1.5$ and negative values in the outer regions of the jet where coflowing air is entrained. In the flame, the peak positive value of the mean radial velocity increases with increasing downstream location, whereas it progressively decreases in the air jet. As a result, the difference between the peak radial velocities in the reacting and non-reacting flows becomes increasingly larger. On the other hand, the minimum values of the mean radial velocity are systematically lower in the air jet than in the flame, indicating a stronger entrainment of the coflowing air into the jet for the non-reacting case. The velocity zero crossings indicate the locations in the mixing layer where the mean outward flow of jet gases merges with the inward flow of entrained air. The radial coordinate of the zero-crossing point diverges from the jet axis as the turbulent jet expands with increasing downstream location, and the rate of divergence is greater in the flame.

The downstream evolution of the velocity fields in the turbulent flames $D_{41}-G_{41}$ and their nonreacting counterparts are summarized in Fig. 4. The entrainment rate and the effects of heat release on the flow field are characterized by outer variables such as the mean and RMS axial velocities along the jet centerline and the jet half-width. In the flames, the mean axial velocity on the jet centerline, $U_{o}$, decreases at a constant rate of approximately $-0.01 U_{\text {bulk }} / D$ between $x / D=0$ and 25, as shown in Fig. 4a. For $x / D \leq 10, U_{o} / U_{\text {bulk }}$ is identical in the flames and air jets, which is partially attributable to the influence of the pilot gases near the nozzle. For $x / D \geq 15, U_{o}$ decays more rapidly in the turbulent air jets than in the flames.

Axial profiles of the jet centerline turbulence intensity, $u_{o}^{\prime} / U_{o}$, are shown in Fig. 4b. Note that the normalization factor used here is the mean centerline axial velocity at the corresponding downstream locations. The centerline turbulence intensity is lower in the turbulent flames than in the turbulent air jets, especially for $x / D \geq 10$. In the air jets, $u_{o}^{\prime} / U_{o}$ rises rapidly between the axial locations of $x / D=5$ and 15 , as result of the shear layer expansion onto the centerline. In the turbulent flames, the centerline 
turbulence intensity increases slowly as a function of downstream location up to nearly $10 \%$ at $x / D=25$. The reaction zone moderates the development of turbulence in the core of the jet. As reported by Pope [53], the centerline turbulence intensity in non-piloted, non-reacting turbulent free jets increases to a plateau value of $25 \%$ in the far-field region. According to the measurements in the piloted air jet, such a turbulence intensity is approximately reached at $x / D=25$.

The streamwise expansion of the turbulent jets is quantified by the full width at half maximum of the radial profile of the mean axial velocity, $\delta$, in Fig. 4c. For $x / D<25$, the turbulent jet flames remain wider than the piloted air jets. At $x / D=25$, the widths of the flames and air jets are approximately equal to $\delta \sim 2.8 D$, and it is expected that the turbulent air jets become wider than the flames further downstream. All four jet flames have approximately the same spread rate of $\partial \delta / \partial x=0.08$, in good agreement with the data reported in Refs. [59, 62]. This near-field spread rate of the flames is significantly smaller than the established far-field spread rate for non-reacting turbulent jets of $\partial \delta / \partial x=0.2[53]$.

The overlap of the respective curves for the flames and air jets in Fig. 4 indicates that the downstream evolution of the normalized centerline velocity statistics from $\mathrm{x} / \mathrm{D}=5$ to 25 is relatively insensitive to the jet exit Reynolds number. The largest deviations occur for the turbulence intensity of the non-reacting jets at $\mathrm{x} / \mathrm{D}=10$. Though not shown, the statistics for flames $F_{61}$ and $F_{81}$ are consistent with those of flames $D_{41}-G_{41}$, indicating that there are no substantial variations in the streamwise evolution of the flow field for the range of Reynolds numbers and stoichiometric mixture fractions investigated.

\subsection{Computations of laminar flame structure and LIF signals}

In order to analyze the scalar measurements in the following sections, we use laminar flame calculations to investigate the chemical structure of the flames and to demonstrate the simulation of $\mathrm{CH}_{2} \mathrm{O}$ and $\mathrm{OH}$ LIF signals. The chemical structures of the partially-premixed DME/air flames are computed using a one-dimensional, steady-state counterflow configuration (Chemkin Oppdif [65]) and two chemical-kinetic mechanisms, namely Kaiser et al., 2000 [21] and Zhao et al., 2008 [22], and their associated transport data. The results of the calculations for a strain rate $a=300 \mathrm{~s}^{-1}$ are plotted in Fig. 5 .

The species profiles calculated for the 4:1 air:DME mixture $\left(\xi_{s t}=0.35\right)$ using different chemical mechanisms are compared in Fig. 5a. Minor differences between the two mechanisms are evident for the major species, $\mathrm{CH}_{3} \mathrm{OCH}_{3}$ (DME), $\mathrm{O}_{2}, \mathrm{H}_{2} \mathrm{O}, \mathrm{CO}_{2}, \mathrm{CO}$ and $\mathrm{H}_{2}$ (Fig. 5a top), as well as for some of the 
intermediate species, $\mathrm{CH}_{3}, \mathrm{H}, \mathrm{OH}$ and $\mathrm{O}$ (Fig. 5a bottom). However, the reaction mechanisms have a larger disparity in the mole fractions of $\mathrm{CH}_{2} \mathrm{O}$ and $\mathrm{CH}_{4}$. For the Zhao mechanism, the peak mole fractions of $\mathrm{CH}_{2} \mathrm{O}$ and $\mathrm{CH}_{4}$ and are $27 \%$ and $32 \%$ larger, respectively, than those of the Kaiser mechanism. Both $\mathrm{CH}_{2} \mathrm{O}$ and $\mathrm{CH}_{4}$ are formed in the decomposition of DME, which occurs by both unimolecular decomposition and abstraction of a hydrogen atom in reactions between DME and radicals such as $\mathrm{H}, \mathrm{OH}, \mathrm{O}$, and $\mathrm{CH}_{3}$. For both chemical-kinetic mechanisms, $\mathrm{CH}_{2} \mathrm{O}$ is predominantly produced by decomposition of the methoxy-methyl radical in the reaction $\mathrm{CH}_{3} \mathrm{OCH}_{2}=\mathrm{CH}_{2} \mathrm{O}+\mathrm{CH}_{3}$. The methoxy-methyl radical is formed by the dominant $\mathrm{H}$-atom abstraction reaction of $\mathrm{DME}+\mathrm{H}=\mathrm{CH}_{3} \mathrm{OCH}_{2}+\mathrm{H}_{2}$. In the Zhao mechanism, the methoxy-methyl radical is also produced by the second most important DME decomposition reaction, $\mathrm{CH}_{3} \mathrm{OCH}_{3}+\mathrm{CH}_{3}=\mathrm{CH}_{3} \mathrm{OCH}_{2}+\mathrm{CH}_{4}$. In contrast, the second most important decomposition reaction in the Kaiser mechanism is $\mathrm{CH}_{3} \mathrm{OCH}_{3}=\mathrm{CH}_{3}+\mathrm{CH}_{3} \mathrm{O}$. The excess production of $\mathrm{CH}_{3} \mathrm{OCH}_{2}$ and $\mathrm{CH}_{4}$ in the Zhao mechanism may explain the difference in the formaldehyde and methane mole fraction profiles for the two mechanisms.

The mole fractions of $\mathrm{CH}_{2} \mathrm{O}$ and $\mathrm{OH}$ in partially-premixed DME/air flames with air:DME ratios of 4:1, 6:1, and 8:1 $\left(\xi_{s t}=0.35,0.48\right.$ and 0.60) are compared in Fig. 5b. The Kaiser mechanism was used for these calculations. As the amount of premixing increases, the reaction zone broadens in the direction of the fuel stream. Although the peak $\mathrm{OH}$ mole fraction is approximately unchanged as $\xi_{s t}$ increases from 0.35 to 0.60 , the distribution of $\mathrm{OH}$ extends further toward the fuel stream. Greater premixing also shifts the distribution of $\mathrm{CH}_{2} \mathrm{O}$ mole fraction toward the fuel stream, and its peak value decreases since the fuel stream contains less DME. Additional laminar flame calculations show that the extension of the $\mathrm{OH}$ distribution and shift in the $\mathrm{CH}_{2} \mathrm{O}$ peak become less pronounced as the strain rate increases above $300 \mathrm{~s}^{-1}$.

The two mechanisms differ somewhat in predictions of flame extinction. The extinction limits of strained laminar flames computed for $\xi_{s t}=0.35,0.48$ and 0.60 are compared for the Kaiser and Zhao reaction mechanisms in Fig. 6. At low strain rates, both reaction mechanisms predict a similar increase in the maximum flame temperature as $\xi_{s t}$ increases. As the strain rate increases, the maximum temperature for the Zhao mechanism decreases faster than for the Kaiser mechanism. The Zhao mechanism predicts an extinction strain rate limit of approximately $800 \mathrm{~s}^{-1}$ for all three mixtures, which is approximately $15 \%$ lower than that of the Kaiser mechanism. Both mechanisms indicate that the extinction strain rate is relatively insensitive to variations in the amount of partial premixing, suggesting that same amount of localized extinction should be observed in the three turbulent flames $F_{41}, F_{61}$ and $F_{81}$. 
The analysis of $\mathrm{CH}_{2} \mathrm{O}$ and OH LIF measurements in the following sections uses the LIF signals themselves without conversion to concentrations. This conversion would require additional simultaneous measurements of the major species and temperature to account for variations in Boltzmann population distributions and collisional quenching rates In order to effectively compare experimental and numerical data, the LIF signals can be computed from the species and temperatures obtained from the simulations and directly compared to the measured LIF signals [31, 32]. Briefly, the simulated OHLIF signal is proportional to the product of the $\mathrm{OH}$ concentration, the Boltzmann population fraction, and the fluorescence quantum yield, which is determined using collisional quenching cross-sections from Tamura et al. [66]. The simulation of CH2O-LIF signals is more complicated and involves greater uncertainty due to the excitation of overlapping transitions and the lack of relevant temperature- and species-dependent quenching data. As described in Refs. 31 and 32, the Boltzmann population distributions of the lower states of the relevant formaldehyde transitions were computed using spectral simulation software [67], and the temperature dependence of the collisional quenching cross-sections were modeled as a power law of $\mathrm{T}^{-0.5}$.

Profiles of computed $\mathrm{CH}_{2} \mathrm{O}$ and $\mathrm{OH}$ LIF signals are included in Fig. $5 \mathrm{~b}$ to demonstrate this approach using the strained laminar flame calculations. The LIF signals are scaled such that the peak LIF signals match the corresponding peaks in the $\mathrm{OH}$ and $\mathrm{CH}_{2} \mathrm{O}$ mole fraction profiles for the flame with $\xi_{s t}=0.35$. The same scaling factors are applied to all three flames. The relative peak heights of the LIF signal profiles correspond very closely to those of the peak mole fractions. The profiles of the $\mathrm{OH}$ LIF signals are shifted slightly toward the oxidizer side relative to the $\mathrm{OH}$ mole fraction profiles, and the $\mathrm{CH}_{2} \mathrm{O}$ LIF signal profiles show an even larger shift relative to the $\mathrm{CH}_{2} \mathrm{O}$ mole fraction profiles. Profiles of the formaldehyde number density (not shown) are shifted closer to the $\mathrm{CH}_{2} \mathrm{O}$ LIF profiles since the temperatures are lower and number densities are larger on the fuel-stream side of the $\mathrm{CH}_{2} \mathrm{O}$ distribution.

\subsection{Scalar Field Statistics}

The scalar fields are first characterized in terms of ensemble statistics of the $\mathrm{OH}$ and $\mathrm{CH}_{2} \mathrm{O}$ LIF imaging measurements performed at locations of $x / D=5,10,15,20$, and 25. For all comparisons of the scalar measurements, the $\mathrm{OH}$ and $\mathrm{CH}_{2} \mathrm{O}$ LIF signals are normalized by the respective peak values of the mean LIF signals in flame $D_{41}$ at $x / D=5$. Single-shot composite images of simultaneous OH LIF and $\mathrm{CH}_{2} \mathrm{O}$ LIF measurements at all downstream locations are displayed in Fig. 7. Iso-contours of the $\mathrm{OH}$ LIF signal are overlaid on the $\mathrm{CH}_{2} \mathrm{O}$ LIF images. The $\mathrm{CH}_{2} \mathrm{O}$ LIF images show that an annular layer of 
$\mathrm{CH}_{2} \mathrm{O}$ forms near the nozzle exit and merges into the core of the jet at approximately $x / D=15$. The $\mathrm{CH}_{2} \mathrm{O}$ LIF images also reveal the presence of highly convoluted small scale structures in the core of the jet, which is indicative of significant turbulent mixing. In contrast, the $\mathrm{OH}$ layers are less corrugated since $\mathrm{OH}$ forms in the less-turbulent, high-temperature region of the reaction zone. The degree of corrugation and fragmentation of the $\mathrm{OH}$ layers increase as the Reynolds number increases. Isolated pockets of $\mathrm{OH}$ that are observed in some images, such as at $x / D=20$ in flame $F_{61}$, can result from flame dynamics subsequent to localized extinction or three-dimensional corrugations of the flame with respect to the imaging plane. Discontinuities in the $\mathrm{OH}$ layers, as observed at $x / D=5$ in flame $G_{41}$, correspond to regions of localized extinction, which occur with greater probability as the Reynolds number increases. The space between fragmented regions of $\mathrm{OH}$ radicals can contain significant $\mathrm{CH}_{2} \mathrm{O}$ LIF signal. The fragmentation of the $\mathrm{OH}$ layers and the separation distance between the $\mathrm{OH}$ and $\mathrm{CH}_{2} \mathrm{O}$ layers are further analyzed in Section 3.4. Overall, the snapshots in Fig. 7 reveal a stark contrast between the structure of the reaction zone in the turbulent flames and that of the laminar counterflow flames presented in Section 3.2. These qualitative discrepancies in the structure may have implications for the applicability of flamelet-based models for turbulent combustion [68].

Radial profiles of the mean and RMS OH LIF and $\mathrm{CH}_{2} \mathrm{O}$ LIF signals, computed using 700-to-1000 LIF snapshots at each downstream location, are plotted for Flame $D_{41}$ in Fig. 8. As the jet flame evolves downstream, the mean OH LIF profile becomes broader and the peak value decreases (Fig. 8a). At the same time, the $\mathrm{CH}_{2} \mathrm{O}$ LIF signal increases along the centerline. In Fig. 8b, the double-peaked profiles of the RMS fluctuations of the OH LIF signal are produced by the corrugations and fluctuations in the position of the $\mathrm{OH}$ LIF layers relative to the burner. The largest fluctuations in the $\mathrm{CH}_{2} \mathrm{O}$ LIF signal occur at the interface with the $\mathrm{OH}$ layers between $r / D=0.5$ and 1.0 , and the magnitude of the fluctuations increases as a function of downstream location.

A comparison of the streamwise evolution of the mean scalar fields in the turbulent flames is plotted in Fig. 9, including variations of the peak mean $\mathrm{OH}$ LIF signal, the mean centerline $\mathrm{CH}_{2} \mathrm{O}$ LIF signal, and the radial location of the peak mean $\mathrm{OH}$ and $\mathrm{CH}_{2} \mathrm{O}$ LIF signals. Figure 9a shows that the maximum value of the mean OH LIF signal at $x / D=5$ decreases with increasing jet exit velocity, by a factor 2 from $D_{41}$ to $G_{41}$, as a result of the increased probability of localized extinction or incomplete ignition by the pilot flame. For $x / D \geq 10$, this peak value is comparable in the four flames with $\xi_{s t}=0.35$. Figure $9 \mathrm{~b}$ shows that the mean centerline $\mathrm{CH}_{2} \mathrm{O}$ LIF signal in all six flames reaches a maximum at $x / D=20$ and decreases further downstream. For the four flames with $\xi_{s t}=0.35$, the centerline $\mathrm{CH}_{2} \mathrm{O}$ LIF signal profiles are identical. For these flames, the axial profiles of both the peak 
mean $\mathrm{OH}$ LIF signal at $x / D \geq 10$ and the mean centerline $\mathrm{CH}_{2} \mathrm{O}$ LIF signal are independent of the Reynolds number.

Larger variations in the streamwise evolution of the LIF signals are observed for the flames with different stoichiometric mixture fractions. For each case in the $F$-flame series, Fig. 9a shows that the peak mean $\mathrm{OH}$ LIF signal varies relatively little as a function of downstream location but increases slightly as $\xi_{s t}$ increases. In contrast, Fig. 9b shows that the centerline mean $\mathrm{CH}_{2} \mathrm{O}$ LIF signal decreases with increasing $\xi_{s t}$ for axial locations of $x / D \geq 15$, indicating that the increased premixing leads to more rapid fuel consumption at these downstream locations.

Figure 9c shows the difference in the evolution of the $\mathrm{OH}$ and $\mathrm{CH}_{2} \mathrm{O}$ layers as the jet flame expands downstream. The peak mean OH LIF signal is displaced radially in all the flames, but the spreading rate is largest in the $D_{41}-G_{41}$ flames and decreases as the amount of premixing increases for flames $F_{61}$ and $F_{81}$. In contrast, the peak mean $\mathrm{CH}_{2} \mathrm{O}$ LIF signal converges to the centerline at approximately $x / D=20$. The rate of convergence increases slightly as the amount of premixing increases.

\subsection{Turbulent Flame Structure}

The structures of the turbulent premixed flames are analyzed in more detail using simultaneous SPIV and $\mathrm{OH}$ LIF measurements as well as simultaneous $\mathrm{CH}_{2} \mathrm{O}$ LIF and $\mathrm{OH}$ LIF imaging. The combined PIV/OH LIF measurements provide conditional statistics on the flow field in the vicinity of the reaction zone. Radial profiles of the mean shear, $\langle\partial u / \partial r\rangle$, conditional on the distance from the interior of the $\mathrm{OH}$ layer are plotted in Fig. 10. The interior boundary of the $\mathrm{OH}$ layer is defined by the iso-contours of normalized OH LIF signal that are equal to 0.24 and located on the side of the OH layer closest to the jet axis. The abscissa in Fig. 10 corresponds to the radial distance from this boundary, with positive and negative values oriented toward the coflow and jet axis, respectively. The magnitude of $\langle\partial u / \partial r\rangle$ in Fig. 10 is normalized by the ratio $U_{b u l k} / R$ for each flame. For all the flames, the profiles of conditional mean shear reach a maximum near the boundary of the $\mathrm{OH}$ layer at $\mathrm{r}=0 \mathrm{~mm}$. The maximum shear decays rapidly from $x / D=5$ to 10 and decreases more gradually further downstream. The decrease in the mean shear is associated with the expansion of the shear layer and the decrease in the axial velocity with increasing downstream location. The comparison of flames $D_{41}, E_{41}, F_{41}$ and $G_{41}$ in Fig. 10 shows that $\langle\partial u / \partial r\rangle$ decreases relative to the ratio $U_{b u l k} / R$ with increasing Reynolds number, even though the absolute value of $\langle\partial u / \partial r\rangle$ is larger in the more turbulent flames. The thickness of the conditional mean shear region across the reaction zone, defined as the FWHM of the radial profiles of 
$\langle\partial u / \partial r\rangle$, increases as a function of downstream location. This shear region thickness varies from $3.5 \mathrm{~mm}$ at $x / D=5$ to $8.5 \mathrm{~mm}$ at $x / D=15$ in flame $D_{41}$ and from $5.0 \mathrm{~mm}$ at $x / D=5$ to $9.8 \mathrm{~mm}$ at $x / D=15$ in flame $G_{41}$. For $x / D \geq 20$, the thickness becomes larger than $11 \mathrm{~mm}$ and could not be determined due to limitations in the field of view of the SPIV/OH LIF measurements. In flames $F_{41}, F_{61}$ and $F_{81}$, however, the profiles of $\langle\partial u / \partial r\rangle$ are quite similar to each other despite the variations in $\xi_{s t}$. Although the increase in premixing for the $F$-flame series shifts the mean location of the reaction zone closer to the jet axis and deeper into the turbulent mixing layer, the local shear at the reaction zone remains essentially unchanged. As a result, the impact of flow shear on the flame chemistry is expected to be comparable for these three flames.

The interplay between combustion chemistry and turbulence in the jet mixing layer can hamper the ignition of reactants by the pilot gases and also cause the formation of burning pockets and extinguished regions, as is evident in the single-shot images of Fig. 7. The effects of the flow field on the flame structure are evaluated by analyzing the number of "holes" in the high-temperature reaction zone, as indicated by discontinuities in the $\mathrm{OH}$ layer. The hole counting procedure is described in detail in Ref. [69], including the limitations of this analysis. In brief, each normalized OH LIF image of dimensions $3.5 D \times 3.5 D$ is smoothed, binarized, and thresholded at a relative signal level of 0.24 . Contiguous regions containing $\mathrm{OH}$ are labeled, and reaction zone holes are identified as the shortest connection between neighboring $\mathrm{OH}$-containing regions with the boundaries of the imaging region treated according to Ref. [69]. The results are used for a comparison of the relative trends in reaction zone morphology for the different turbulent flames since the exact number of holes depends to some extent on the choice of signal threshold and is subject to inherent uncertainties. When the reaction zone is not strongly affected by the flow field, as exemplified in the snapshot in Fig. 7 for flame $D_{41}$ centered at $x / D=5$, the OH LIF layer is singly-connected and zero holes are counted for that snapshot. However, more intense turbulence-chemistry interactions fragment the $\mathrm{OH}$ layer and the number of holes per snapshot increases. For instance, the snapshot for flame $G_{41}$ at $\mathrm{x} / \mathrm{D}=5$ in Fig. 7 has two holes with three regions containing $\mathrm{OH}$.

Probability density functions (PDFs) of the number of holes per OH LIF image and their variation with flow conditions and downstream position are shown in Fig. 11. The PDFs for flames $D_{41}$ to $G_{41}$ show a progression of increasing probability of hole formation as the turbulence and flow shear increase. The probability of finding zero reaction zone holes at $x / D=5$ decreases from approximately $99 \%$ in flame $D_{41}$ to $3 \%$ in flame $G_{41}$, and the most probable number of holes per snapshot shifts from 0 to 2 . 
The increased probability of hole formation at the higher Reynolds numbers can result from a combination of localized extinction and incomplete ignition of the reactants by the pilot gases.

The downstream evolution of the PDFs varies somewhat amongst the different flames. In flames $D_{41}$ and $E_{41}$, the probability of finding zero holes is greatest at $x / D=5$, where localized extinction and isolated pockets of $\mathrm{OH}$ radicals are relatively rare. Further downstream, the probability of detecting one or more holes per image increases because of a combination of increased localized extinction, flame pockets, and three-dimensional flame convolution. This result may appear to contradict the expectation that regions of the reaction zone that are closer to the nozzle would be disrupted by the higher shear at $x / D=5$ (Fig. 10); however, combustion in the near field is actively supported by the pilot gases. However, this support becomes less robust at the larger flow rates in flames $F_{41}$ and $G_{41}$. In these flames, the largest probability of detecting discontinuities in the reaction zone occurs at $x / D=5$, and it decreases further downstream as the strain rate and shear decrease (Fig. 10).

The PDFs for flames $F_{41}, F_{61}$, and $F_{81}$ show relatively small variations in the probability of fragmentation of the $\mathrm{OH}$ layers, although the probability decreases slightly with increased premixing. These variations are most pronounced at $x / D=5-10$. The difference in extinction probability within the $F$-flame series is not the result of the flow shear since the data in Fig. 10 show that the shear at the reaction zone is comparable in these flames. The increased premixing represents a progression from partially-premixed combustion to fully-premixed combustion, although even the largest amount of premixing with air:DME $=8: 1$ results in an equivalence ratio of 1.8 and a relatively small flame speed on the order of $10 \mathrm{~cm} / \mathrm{s}[23,28]$.

The effect of turbulent transport on distributions of combustion intermediate species is a key aspect of turbulence-chemistry interactions. The single-shot images in Fig. 7 show that the spatial overlap between formaldehyde and $\mathrm{OH}$ can fluctuate significantly within the series of turbulent flames. In some instances, the two species are located in close proximity, whereas in other instances, there are large gaps between the two species (e.g. snapshots of flames $E_{41}, F_{41}, F_{61}$ at $x / D=25$ ). The degree of overlap can affect the local reaction rates of these species, and the proximity of formaldehyde to the extinguished regions may affect the delay times for re-ignition. Extinguished regions can contain significant amounts of formaldehyde, as seen in the single-shot $\mathrm{CH}_{2} \mathrm{O} / \mathrm{OH}$ LIF image at $x / D=5$ for flame $G_{41}$.

The average separation distance between regions containing $\mathrm{CH}_{2} \mathrm{O}$ and $\mathrm{OH}$ increases as a function of downstream position, as shown in Fig. 9c. The fluctuating separation distance between the $\mathrm{CH}_{2} \mathrm{O}$ and $\mathrm{OH}$ distributions is quantified in each simultaneous $\mathrm{CH}_{2} \mathrm{O} / \mathrm{OH}$ LIF snapshot following the approach described in Ref. [31]. The resulting PDFs of $\mathrm{CH}_{2} \mathrm{O}-\mathrm{OH}$ separation distances for the entire dataset are 
plotted in Fig. 12. The PDFs are computed using a bin size of $18.9 \mu \mathrm{m}$, which equals the projected pixel size for the $\mathrm{CH}_{2} \mathrm{O}$ LIF imaging measurements. For this analysis, the outer boundary of the $\mathrm{CH}_{2} \mathrm{O}$ distribution and inner boundary of the $\mathrm{OH}$ layer are defined using the iso-contours of normalized LIF signals equal to 0.24. Although the PDFs depend to some extent on the iso-contour value that is used to determine the boundaries, the trends observed in Fig. 12 remain consistent with different values. For all the flames, the peaks of the PDFs are centered approximately at $0 \mathrm{~mm}$. Except for flame $F_{81}$, the PDFs are noticeably skewed toward positive values, indicating that the $\mathrm{CH}_{2} \mathrm{O}$ and $\mathrm{OH}$ layers are preferentially separated. The PDF distributions broaden and extend toward larger positive values with increasing downstream location. Therefore, the separation between the two intermediate species increases with downstream location in concert with the decrease in mean shear (Fig. 10). The largest separation distances are measured in flame $D_{41}$, and the PDF distribution tends to narrow with increasing bulk jet flow rate, which corresponds to increasing mean shear. These results are consistent with previous calculations of laminar partially premixed flames that show a reduction in separation distance with increases in strain rate [32]. The separation distance also decreases with increasing stoichiometric mixture fraction in flames $F_{41}$ to $F_{81}$, which is consistent with the laminar flame calculations in Fig. $5 \mathrm{~b}$ and the mean separation distance measurements in Fig. 9c.

\section{Conclusions}

Measurements in a series of piloted, turbulent partially-premixed DME/air jet flames were presented for varying Reynolds numbers and stoichiometric mixture fractions. These flames provide a framework for the development and validation of turbulent combustion models and simulation schemes. The flow field was determined using stereo-PIV, and the turbulent flame structure was measured using $\mathrm{CH}_{2} \mathrm{O}$ and $\mathrm{OH}$ LIF imaging. Measurements were performed in the near-field region of the jets for $x / D \leq 25$, where strong variability of the velocity and LIF signal statistics were observed with downstream locations.

Ensemble mean and RMS statistics of the velocity components and the $\mathrm{CH}_{2} \mathrm{O}$ and $\mathrm{OH}$ LIF signals were self-consistent across the range of Reynolds numbers, but the distribution of the mean LIF signals varied as a function of the stoichiometric mixture fraction. Simultaneous PIV and OH LIF measurements were used to evaluate conditional velocity gradients, enabling an analysis of the local shear at the reaction zone in each of the turbulent jet flames. The reaction zones in the jet flames that 
had stoichiometric mixture fractions ranging from $\xi_{s t}=0.35$ to 0.60 experienced essentially the same amount of shear despite differences in the mean location of the flame within the jet mixing layer. The relationship between the topology of $\mathrm{CH}_{2} \mathrm{O}$ and $\mathrm{OH}$ was investigated using simultaneous imaging of $\mathrm{CH}_{2} \mathrm{O}$ and $\mathrm{OH}$ LIF. The combined measurements revealed that the regions occupied by these intermediate species are subject to maximum shear and that the flame structure can be highly disrupted by the flow field with formation of locally extinction regions and isolated pockets of $\mathrm{OH}$ radicals. In addition, there are large intermittent fluctuations in the separation distances between these species.

The scalar and velocity data will be made available for model development by contacting the authors.

\section{Acknowledgments}

The authors are grateful to Prof. M.G. Mungal for contributions to the experiments and Mr. E. Huang for technical assistance in the laboratory. This research was supported by the U.S. Department of Energy, Office of Basic Energy Sciences, Division of Chemical Sciences, Geosciences, and Biosciences. Sandia National Laboratories is a multiprogram laboratory operated by Sandia Corporation, a Lockheed Martin Company, for the U.S. Department of Energy under contract DE-AC04-94-AL85000. S.K. Im and M. Gamba were supported by the Department of energy under Award Number DE-FC08NA28614. 


\section{References}

1 Arcoumanis, C., Bae, C., Crookes, R., Kinoshita, E., The potential of di-methyl ether (DME) as an alternative fuel for compression-ignition engines: A review, Fuel 87 (2008) 1014-1030.

2 Park, S.H., Lee, C.S., Combustion performance and emission reduction characteristics of automotive DME engine system, Prog. Energy Combust. Sci. 39 (2013) 147-168.

3 Thomas, G., Feng, B., Veeraragavan, A., Cleary, M.J., Drinnan, N., Emissions from DME combustion in diesel engines and their implications on meeting future emission norms: A review, Fuel Process. Technol. 119 (2014) 286-304.

4 Lu, X., Han, D., Huang, Z., Fuel design and management for the control of advanced compressionignition combustion mode, Prog. Energy Combust. Sci. 37 (2011) 741-783.

5 Park, S.H., Lee, C.S., Combustion performance and emission reduction characteristics of automotive DME engine system, Prog. Energy Combust. Sci. 39 (2013) 147-168.

6 TNF Workshop, http://www.ca.sandia.gov/TNF, Barlow, R.S., Eds., Sandia National Laboratories.

7 Masri, A.R., Dibble, R.W., Barlow, R.S., The structure of turbulent nonpremixed flames revealed by Raman-Rayleigh-LIF measurements, Prog. Energy Combust. Sci. 22 (1996) 307-362.

8 Barlow, R.S., Frank, J.H., Effects of turbulence on species mass fraction in methane/air jet flames, Proc. Combust. Inst. 27 (1998) 1087-1095.

9 Schneider, C., Dreizler, A., Janicka, J., Hassel, E.P., Flow field measurements of stable and locally extinguishing hydrocarbon-fueled jet flames, Combust. Flame 135 (2003) 185-190.

10 Barlow, R.S., Frank, J.H., Karpetis, A.N., Chen, J.-Y., Piloted methane/air jet flames: Transport effects and aspects of scalar structure, Combust. Flame 143 (2005) 433-449.

11 Lindstedt, R.P., Louloudi, S.A., Vaós, E.M., Joint scalar probability density function modeling of pollutant formation in piloted turbulent jet diffusion flames with comprehensive chemistry, Proc. Combust. Inst. 28 (2000) 149-156.

$12 \mathrm{Xu}$, J., Pope, S.B., PDF calculations of turbulent nonpremixed flames with local extinction, Combust. Flame 123 (2000) 281-307.

13 Pitsch, H., Improved pollutant predictions in large-eddy simulations of turbulent non-premixed combustion by considering scalar dissipation rate fluctuations, Proc. Combust. Inst. 29 (2002) 19711978. 
14 Kempf, A., Flemming, F., Janicka, J., Investigation of lengthscales, scalar dissipation, and flame orientation in a piloted diffusion flame by LES, Proc. Combust. Inst. 30 (2005) 557-565.

15 Ihme, M., Pitsch, H., Prediction of extinction and reignition in nonpremixed turbulent flames using a flamelet/progress variable model 2. Application in LES of Sandia flames D and E, Combust. Flame 155 (2008) 90-107.

16 Gabet, K.N., Shen, H., Patton, R.A., Fuest, F., Sutton, J.A., A comparison of turbulent dimethyl ether and methane non-premixed flame structure, Proc. Combust. Inst. 34 (2013) 1447-1454.

17 Fuest, F., Barlow, R.S., Chen, J.-Y., Dreizler, A., Raman/Rayleigh scattering and CO-LIF measurements in laminar and turbulent jet flames of dimethyl ether, Combust. Flame 159 (2012) 2533-2562.

18 Fuest, F., Magnotti, G., Barlow, R.S., Sutton, J.A., Scalar structure of turbulent partially-premixed dimethyl ether/air jet flames, Proc. Combust. Inst. 35 (2015) 1235-1242.

19 Guiberti, T.F., Juddoo, M., Lacoste, D.A., Dunn, M.J., Roberts, W.L., Masri, A.R., Fuel effects on the stability of turbulent flames with compositionally inhomogeneous inlets, Proc. Combust. Inst. (2016), http://dx.doi.org/10.1016/j.proci.2016.08.051.

20 Fischer, S.L., Dryer, F.L., Curran, H.J., The reaction kinetics of dimethyl ether. I: High-temperature pyrolysis and oxidation in flow reactors, Int. J. Chem. Kinet. 32 (2000) 713-740.

21 Kaiser, E.W., Wallington, T.J., Hurley, M.D., Platz, J., Curran, H.J., Pitz, W.J., Westbrook, C.K., Experimental and modeling study of premixed atmospheric-pressure dimethyl ether-air flames, Phys. Chem. A. 104 (2000) 8194-8206.

22 Zhao, Z., Chaos, M., Kazakov, A., Dryer, F.L., Thermal decomposition reaction and a comprehensive kinteic model o dimethyl ether, Int. J. Chem. Kin., 40 (2008) 1-18.

23 Daly, C.A., Simmie, J.M., Wurmel, J., Djeballi, N., Paillard, C., Burning velocities of dimethyl ether and air, Combust. Flame 125 (2001) 1329-1340.

24 Zhao, Z., Kazakov, A., Dryer, F.L., Measurements of dimethyl ether/air mixture burning velocities by using particle image velocimetry, Combustion and Flame 139 (2004) 52-60.

25 Zheng, X.L., Lu, T.F., Law. C.K., Westbrook, C.K., Curran, H.J., Experimental and computational study of nonpremoxed ignition of dimethyl ether in counterflow, Proc. Combust. Inst. 30 (2005) 1101-1109. 
26 Qin, X., Ju, Y., Measurements of burning velocities of dimethyl ether and air premixed flames at elevated pressures, proc. Combust. Inst. 30 (2005) 233-240.

27 Mittal, G., Chaos, M., Sung, C.-J., Dryer, F.L., Dimethyl ether autoignition in a rapid compression machine: Experiments and chemical kinetic modeling, Fuel Proc. Tech. 89 (2008) 1244-1254.

28 Wang, Y.L., Holley, A.T., Egolfopoulos, F.N., Tsotsis, T.T., Curran, H.J., Propagation and extinction of premixed dimethyl ether/air flames, Proc. Combust. Inst. 32 (2009) 1035-1042.

29 de Vries, J., Lowry, W.B., Serinyel, Z., Curran H.J., Petersen, E.L., Laminar flame speed measurements of dimethyl ether in air at pressures up to 10 atm, Fuel 90 (2011) 331-338.

30 Chen, Z., Tang, C., Fu, J., Jiang, X., Li, Q., Wei, L., Huang, Z., Experimental and numerical investigation on diluted DME flames: Thermal and chemical kinetic effects on laminar flame speeds, Fuel 102 (2012) 567-573.

31 Coriton, B., Zendehdel, M., Ukai, S., Kronenburg, A., Stein, O.T., Im, S.-K., Gamba, M., Frank, J.H., Imaging measurements and LES-CMC modeling of a partially-premixed turbulent dimethyl ether/air jet flame, Proc. Combust. Inst. 35 (2015) 1251-1258.

32 Popp, S., Hunger, F., Hartl, S., Messig, D., Coriton, B., Frank, J.H., Fuest, F., Hasse, C., LES flamelet-progress variable modeling and measurements of a turbulent partially-premixed dimethyl ether jet flame, Combust. Flame 162 (2015) 3016-3029.

33 Gabet, K.N., Sutton, J.A., Narrowband versus broadband excitation for $\mathrm{CH}_{2} \mathrm{O}$ PLIF imaging in flames using a frequency-tripled Nd:YAG laser, Exp. Fluids 55 (2014) 1774.

34 Brackmann, C., Bood, J., Aldén, M., Pengloan, G., Andersson, Ö., Quantitative measurements of species and temperature in a DME-air counterflow diffusion flame using laser diagnostic methods, Combust. Sci. and Tech. 178 (2006) 1165-1184.

35 Wieneke, B., Stereo-PIV using self-calibration on particle images, Exp. Fluids 39 (2005) 267-280.

36 Scarano, F., Theory of non-isotropic spatial resolution in PIV, Exp. Fluids 35 (2003) 268-277.

37 Westerweel, J., Scarano, F., Universal outlier detection for PIV data, Exp. in Fluids 39 (2005) 10961100.

38 Garcia, D., A fast all-in-one method for automated post-processing of PIV data, Exp. Fluids 50 (2011) 1247-1259. 
39 Westerweel, J., Dabiri, D., Gharib, M., The effect of a discrete window offset on the accuracy of cross-correlation analysis of digital PIV recordings, Exp. Fluids 23 (1997) 20-28.

40 Huang, H., Dabiri, D., Gharib, M., On errors of digital particle image velocimetry, Meas. Sci. Technol. 8 (1997) 1427-1440.

41 Westerweel, J., Theoretical analysis of the measurement precision in particle image velocimetry, Exp. Fluids 29 (2000) S003-S012.

42 Nobach, H., Bodenschatz, E., Limitations of accuracy in PIV due to individual variations of particle image intensities, Exp. Fluids 47 (2009) 27-38.

43 Prasad, A.K., Stereoscopic particle image velocimetry, Exp. Fluids 29 (2000) 103-116.

44 Wilson, B.M., Smith, B.L., Uncertainty on PIV mean and fluctuating velocity due to bias and random errors, Meas. Sci. Technol. 14 (2013) 035302.

45 Westerweel, J., On velocity gradients in PIV interrogation, Exp. Fluids 44 (2008) 831-842.

46 Foucault, J.M., Carlier, J., Stanislas, M., PIV optimization for the study of turbulent flow using spectral analysis, Meas. Sci. Technol. 15 (2004) 1046-1058.

47 Lavoie, P., Avallone, G., De Gregorio, F., Romano, G.P., Antonia, R.A., Spatial resolution of PIV for the measurement of turbulence, Exp. Fluids 43 (2007) 39-51.

48 Worth, N.A., Nickels, T.B., Swaminathan, N., A tomographic PIV resolution study based on homogeneous isotropic turbulence DNS data, Exp. Fluids 49 (2010) 637-656.

49 Buch, K.A., Dahm, W.J.A., Experimental study of the fine-scale structure of conserved scalar mixing in turbulent shear flows. Part 2. Sc $\approx 1$, J. Fluid Mech. 364 (1998) 1-29.

50 Frank, J.H., Kaiser, S.A., High-resolution imaging of turbulence structures in jet flames and nonreacting jets with laser Rayleigh scattering, Exp. Fluids 49 (2010) 823-837.

51 Wang, G., Karpetis, A.N., Barlow, R.S., Dissipation length scales in turbulent nonpremixed jet flames, Combust. Flame 148 (2007) 62-75.

52 Abramovich, G.N., The theory of turbulent jets, M.I.T. Press, Massachusetts, USA, 1963.

53 Pope, S.B., Turbulent Flows, Cambridge University Press, Cambridge, UK, 2000.

54 Ball, C.G., Fellouah, H., Pollard, A., The flow field in turbulent round free jets, Prog. Aerospace Sci. 50 (2012) 1-26. 
55 Becker, H.A., Yamazaki, S., Entrainment, momentum flux and temperature in vertical free turbulent diffusion flames, Combust. Flame 33 (1978) 123-149.

56 Takagi, T., Shin, H.-D., Ishio, A., Properties of Turbulence in Turbulent Diffusion Flames, Combust. Flame 40 (1981) 121-140.

57 Sislian, J.P., Jiang, L.-Y., Cusworth, R.A., Laser Doppler velocimetry investigation of the turbulence structure of axisymmetric diffusion flames, Prog. Energ. Combust. Sci. 14 (1988) 99-146.

58 Clemens, N.T., Paul, P.H., Effects of heat release on the near field flow structure of hydrogen jet diffusion flames, Combust. Flame 102 (1995) 271-284.

59 Tacina, K.M., Dahm, W.J.A., Effects of heat release on turbulent shear flows. Part 1. A general equivalence principle for non-buoyant flows and its application to turbulent jet flames, J. Fluid Mech. 415 (2000) 23-44.

60 Han, D., Mungal, M.G., Direct measurements of entrainment in reacting/nonreacting turbulent jets, Combust. Flame 124 (2001) 370-386.

61 Donbar, J.M., Driscoll, J.F., Carter, C.D., Strain rates measured along the wrinkled flame contour within turbulent non-premixed jet flames, Combust. Flame 125 (2001) 1239-1257.

62 Han, D., Mungal, M.G., Simultaneous measurements of velocity and CH distributions. Part 1: jet flames in co-flow, Combust. Flame 132 (2003) 565-590.

63 Diez, F.J., Dahm, W.J.A., Effects of heat release on turbulent shear flows. Part3. Buoyancy effects due to heat release in jets and plumes, J. Fluid Mech. 575 (2007) 221-255.

64 Coriton, B., Frank, J.H., Experimental study of vorticity - strain rate interaction in turbulent partially-premixed jet flames using tomographic PIV, Phys. Fluids 28 (2016) 025109.

65 Kee, R.J., Rupley, F.M., Miller, J.A., Coltrin, M.E., Grcar, J.F., Meeks, E., Moffat, H.K., Lutz, A.E., Dixon-Lewis, G., Smooke, M.D., Warnatz, J., Evans, G.H., Larson, R.S., Mitchell, R.E., Petzold, L.R., Reynolds, W.C., Caracotsios, M., Stewart, W.E., Glarborg, P., in, Reaction Design, Inc., San Diego, CA, 2007.

66 Tamura, M., Berg, P.A., Harrington, J.E., Luque, J., Jeffries, J.B., Smith, G.P., Crosley, D.R., Collisional quenching of $\mathrm{CH}(\mathrm{A}), \mathrm{OH}(\mathrm{A})$ and $\mathrm{NO}(\mathrm{A})$ in low pressure hydrocarbon flames, Combustion and Flame 114 (1998) 502-514. 
67 Judge, R.H., Clouthier, D.J., “AsyrotWin: a 32-bit Windows version of Asyrot, a program for the analysis of high resolution singlet-singlet band spectra of asymmetric tops", Comput. Phys. Commun. 135 (2001) 293-311.

68 Peters, N., Laminar diffusion flamelet models in non-premixed turbulent combustion, Prog. Energ. Combust. Sci. 10 (1984) 319-339.

69 Kaiser, S.A., Frank, J.H., Spatial scales of extinction and dissipation in the near field of nonpremixed turbulent jet flames, Proc. Combust. Inst. 32 (2009) 1639-1646. 
Tables

Table 1 - Turbulent flame conditions.

\begin{tabular}{c|cccc}
\hline Flame & $\boldsymbol{\varphi}_{\text {jet }}$ & $\boldsymbol{\xi}_{\text {st }}$ & $\boldsymbol{R e}_{\boldsymbol{D}}$ & $\begin{array}{c}\boldsymbol{U}_{\text {bulk }} \\
(\boldsymbol{m} / \boldsymbol{s})\end{array}$ \\
\hline $\boldsymbol{D}_{\boldsymbol{4 1}}$ & 3.6 & 0.35 & 29,300 & 45.9 \\
$\boldsymbol{E}_{\boldsymbol{4 1}}$ & 3.6 & 0.35 & 44,000 & 68.8 \\
$\boldsymbol{F}_{\boldsymbol{4 1}}$ & 3.6 & 0.35 & 58,600 & 91.8 \\
$\boldsymbol{F}_{\boldsymbol{6 1}}$ & 2.4 & 0.48 & 54,600 & 91.8 \\
$\boldsymbol{F}_{\boldsymbol{8 1}}$ & 1.8 & 0.60 & 52,500 & 91.8 \\
$\boldsymbol{G}_{\boldsymbol{4 1}}$ & 3.6 & 0.35 & 73,300 & 115. \\
\hline
\end{tabular}

Table 2 - Pilot mixture composition.

\begin{tabular}{cccccc}
\hline$X\left(\mathrm{CO}_{2}\right)$ & $X\left(\mathrm{~N}_{2}\right)$ & $X\left(\mathrm{C}_{2} \mathrm{H}_{2}\right)$ & $X\left(\mathrm{H}_{2}\right)$ & $\boldsymbol{X}\left(\mathrm{O}_{2}\right)$ & $\varphi_{\text {pilot }}$ \\
\hline 0.030 & 0.688 & 0.022 & 0.088 & 0.172 & 0.6 \\
\hline
\end{tabular}




\section{List of Figures}

Figure 1 - Flame photographs (exposure time: 1.0 ms).

Figure 2 - Experimental configurations for (a) simultaneous $\mathrm{CH}_{2} \mathrm{O} / \mathrm{OH} \mathrm{LIF}$ and (b) simultaneous PIV/OH LIF measurements.

Figure 3 - Radial profiles of mean and RMS axial velocities and mean radial velocity in piloted air

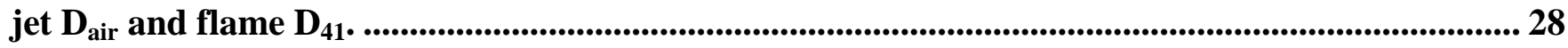

Figure 4 - Comparison of centerline velocity measurements in flames $D_{41}, E_{41}, F_{41}$ and $G_{41}$. Profiles of a) $U_{0} / U_{b u l k}$ b) $u_{0}{ }^{\prime} / U_{0}$ and c) $\delta$ (FWHM of $U$ radial profiles). Note that the normalization factor in Fig. $4 \mathrm{~b}$ is the mean centerline velocity at each downstream location, $U_{0} . .29$

Figure 5 - Flame structure calculated for $a=300 / \mathrm{s}$ using Chemkin Oppdif [65]. a) Comparison of species mole fractions computed using the Zhao (solid) [22] and Kaiser (dashed) [21] reaction mechanisms. b) Profiles of $\mathrm{OH}$ and $\mathrm{CH}_{2} \mathrm{O}$ mole fractions for $\xi_{\mathrm{st}}=0.35$ (solid), 0.48 (dashed) and 0.60 (dotted) computed using the Kaiser mechanism. Profiles of simulated $\mathrm{OH}$ and $\mathrm{CH}_{2} \mathrm{O}$ LIF signals. 30

Figure 6 - Strained laminar flame extinction limits computed using Chemkin Oppdif [65] and compared for the Zhao (solid) [22] and Kaiser (dashed) [21] reaction mechanisms. Calculated maximum laminar flame temperatures plotted as a function strain rate for $\xi_{\mathrm{st}}=0.35$ (blue), 0.48 (black) and 0.60 (red). 31

Figure 7 - Examples of single-shot $\mathrm{OH}$ LIF and $\mathrm{CH}_{2} \mathrm{O}$ LIF measurements at locations of $x / D=5$, $10,15,20$ and 25 in all six turbulent flames. Images of the $\mathrm{CH}_{2} \mathrm{O}$ LIF signal are overlapped with OH LIF signal iso-contours for OHLIF $=0.24$ to 1.92 in steps of 0.24 . Dashed vertical lines indicate the jet centerline. 32

Figure 8 - Radial profiles of mean and RMS OH LIF (solid) and $\mathrm{CH}_{2} \mathrm{O}$ LIF (dashed) signals in flame $\mathbf{D}_{41}$. .33

Figure 9 - Comparison of a) peak mean $\mathrm{OH}$ LIF signal, b) centerline mean $\mathrm{CH}_{2} \mathrm{O}$ LIF signal and c) radial position of peak mean LIF signals in all the turbulent flames. 34

Figure 10 - Mean radial gradient of the axial velocity conditional on OH LIF iso-contours of 0.24 . Velocity gradients are normalized by $U_{\text {bulk }} / \mathbb{R}$ for each flame. 35

Figure 11 - Number of reaction zone holes per OH LIF snapshot in the turbulent flames. 36

Figure 12 - PDFs of the spacing between the $\mathrm{CH}_{2} \mathrm{O}$ and $\mathrm{OH}$ LIF layers in the turbulent flames. Negative values indicate that the layers are overlapping. 37 
Figure 1 - Flame photographs (exposure time: $1.0 \mathrm{~ms}$ ).

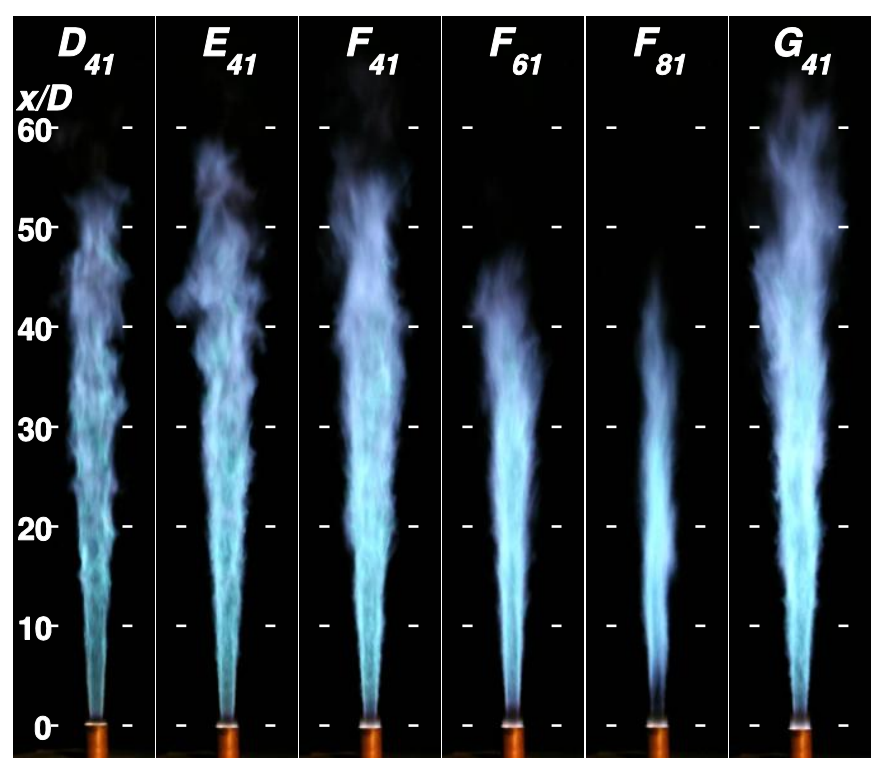


Figure 2 - Experimental configurations for (a) simultaneous $\mathrm{CH}_{2} \mathrm{O} / \mathrm{OH} \mathrm{LIF}$ and (b) simultaneous PIV/OH LIF measurements.

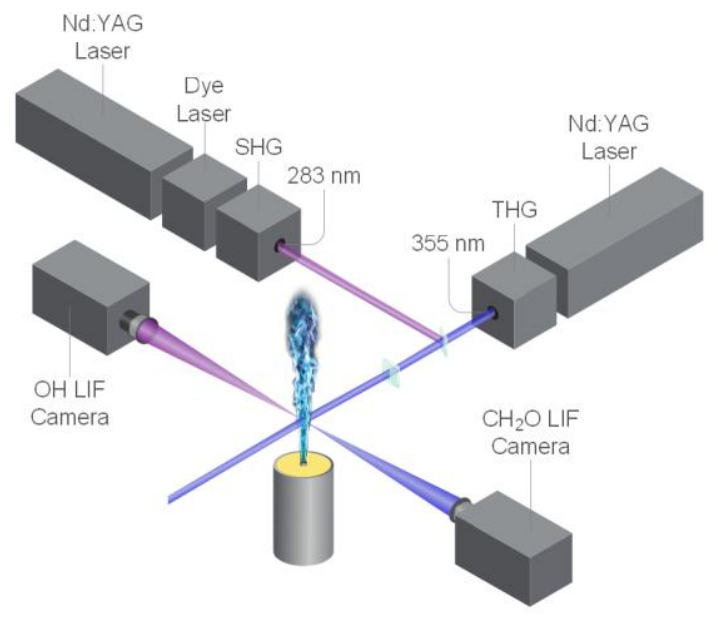

(a)

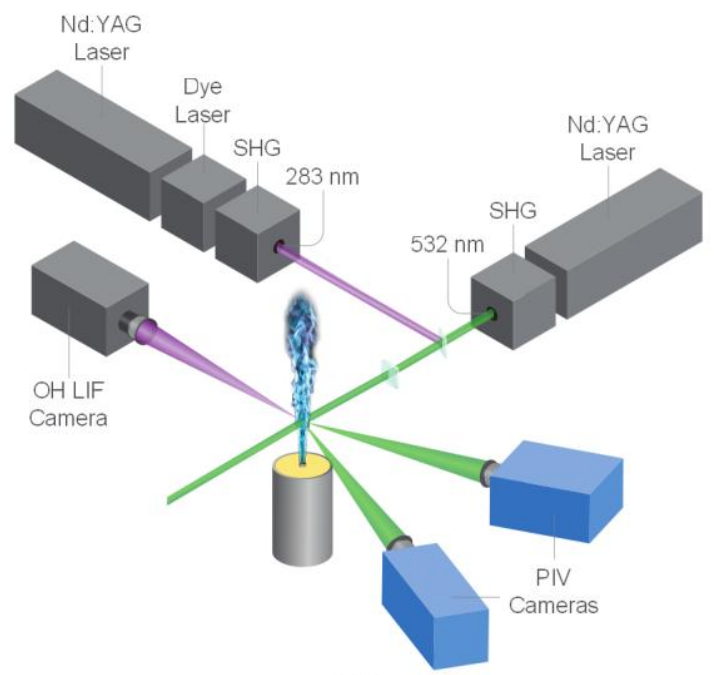

(b) 
Figure 3 - Radial profiles of mean and RMS axial velocities and mean radial velocity in piloted air jet $D_{a i r}$ and flame $D_{41}$.
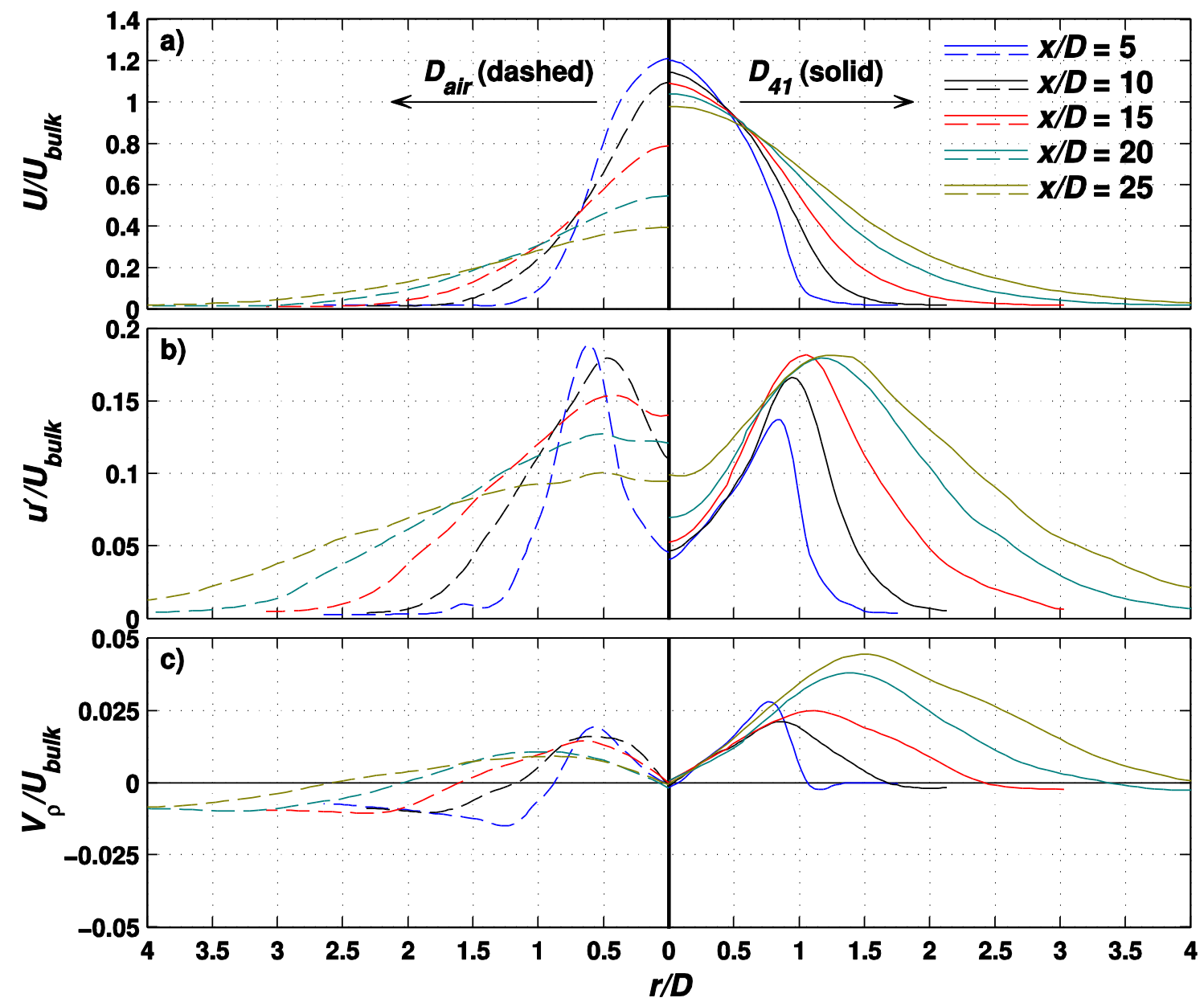
Figure 4 - Comparison of centerline velocity measurements in flames $D_{41}, E_{41}, F_{41}$ and $G_{41}$. Profiles of a) $U_{o} / U_{b u l k}$, b) $u_{o}{ }^{\prime} / U_{o}$ and c) $\delta$ (FWHM of $U$ radial profiles). Note that the normalization factor in Fig. $4 \mathrm{~b}$ is the mean centerline velocity at each downstream location, $U_{o}$.

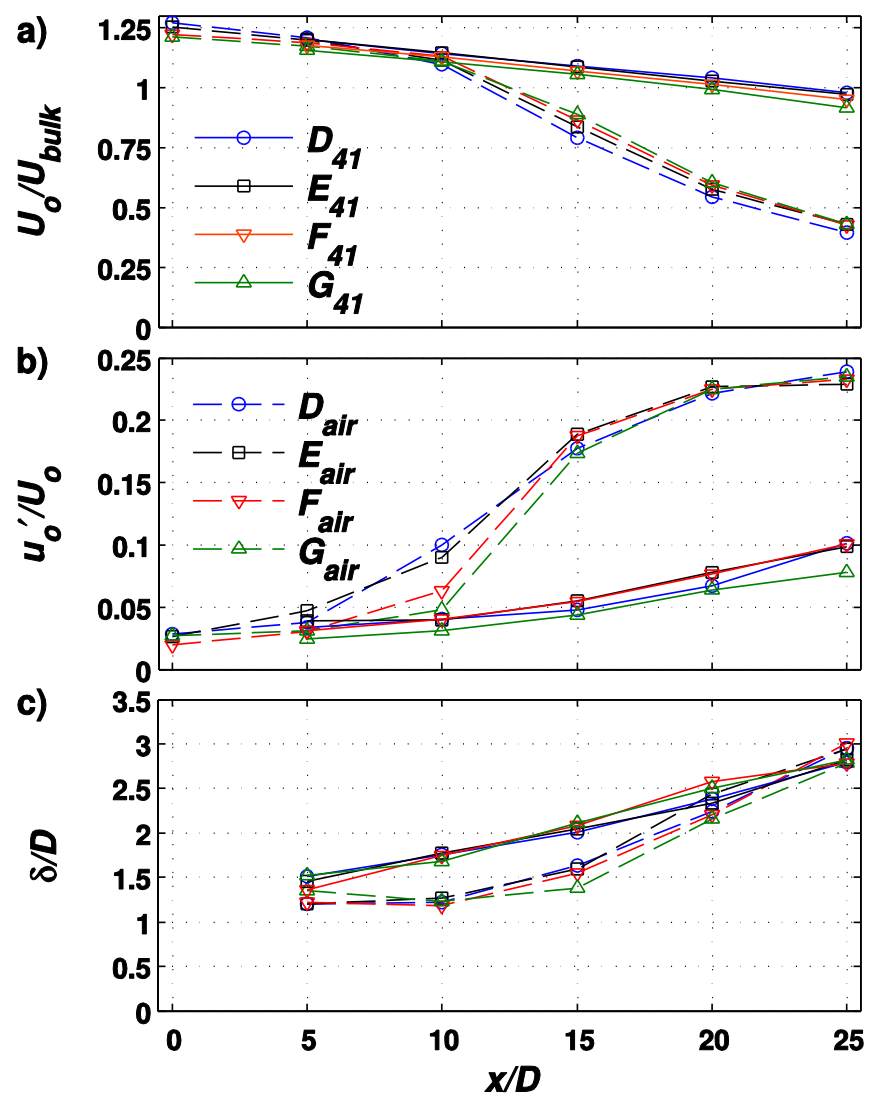


Figure 5 - Flame structure calculated for $a=300 / \mathrm{s}$ using Chemkin Oppdif [65]. a) Comparison of species mole fractions computed using the Zhao (solid) [22] and Kaiser (dashed) [21] reaction mechanisms. b) Profiles of $\mathrm{OH}$ and $\mathrm{CH}_{2} \mathrm{O}$ mole fractions for $\xi_{s t}=0.35$ (solid), 0.48 (dashed) and 0.60 (dotted) computed using the Kaiser mechanism. Profiles of simulated $\mathrm{OH}$ and $\mathrm{CH}_{2} \mathrm{O} \mathrm{LIF}$ signals.
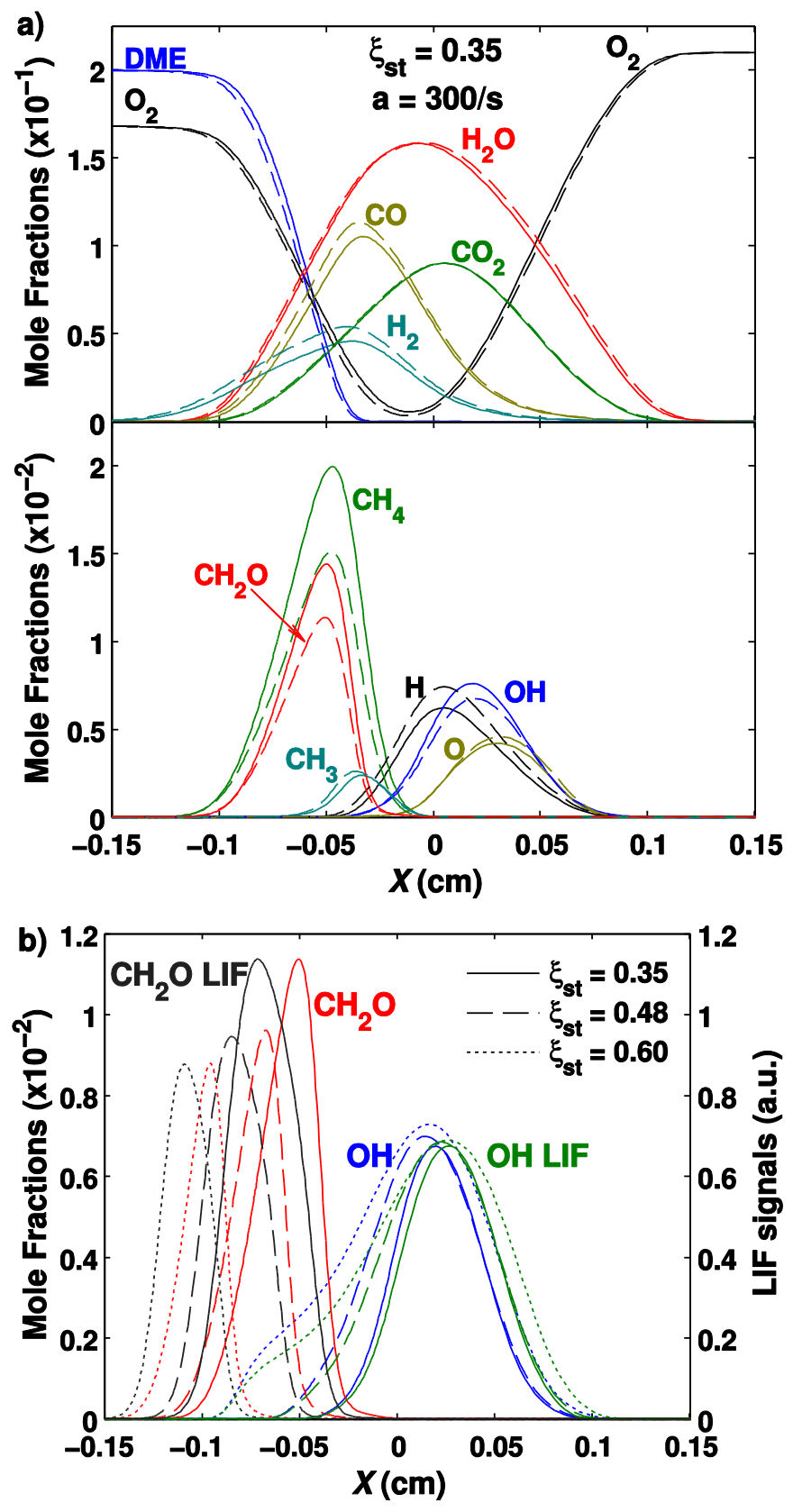
Figure 6 - Strained laminar flame extinction limits computed using Chemkin Oppdif [65] and compared for the Zhao (solid) [22] and Kaiser (dashed) [21] reaction mechanisms. Calculated maximum laminar flame temperatures plotted as a function strain rate for $\xi_{s t}=0.35$ (blue), 0.48 (black) and 0.60 (red).

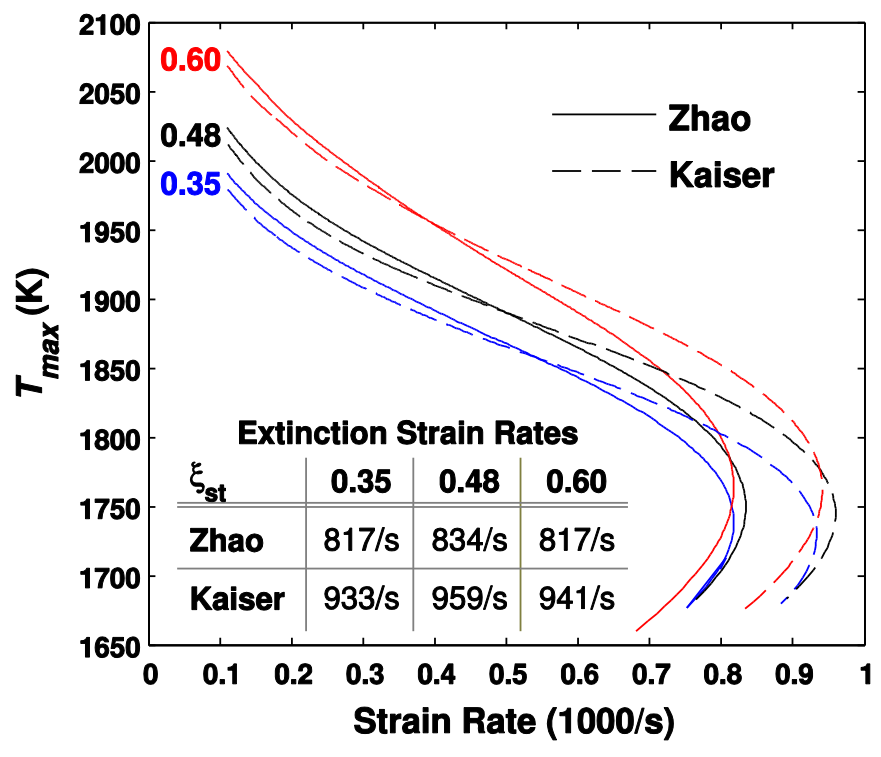


Figure 7 - Examples of single-shot $\mathrm{OH} \mathrm{LIF} \mathrm{and} \mathrm{CH}_{2} \mathrm{O}$ LIF measurements at locations of $x / D=5$, 10, 15, 20 and 25 in all six turbulent flames. Images of the $\mathrm{CH}_{2} \mathrm{O}$ LIF signal are overlapped with OH LIF signal iso-contours for OHLIF $=0.24$ to 1.92 in steps of 0.24 . Dashed vertical lines indicate the jet centerline.

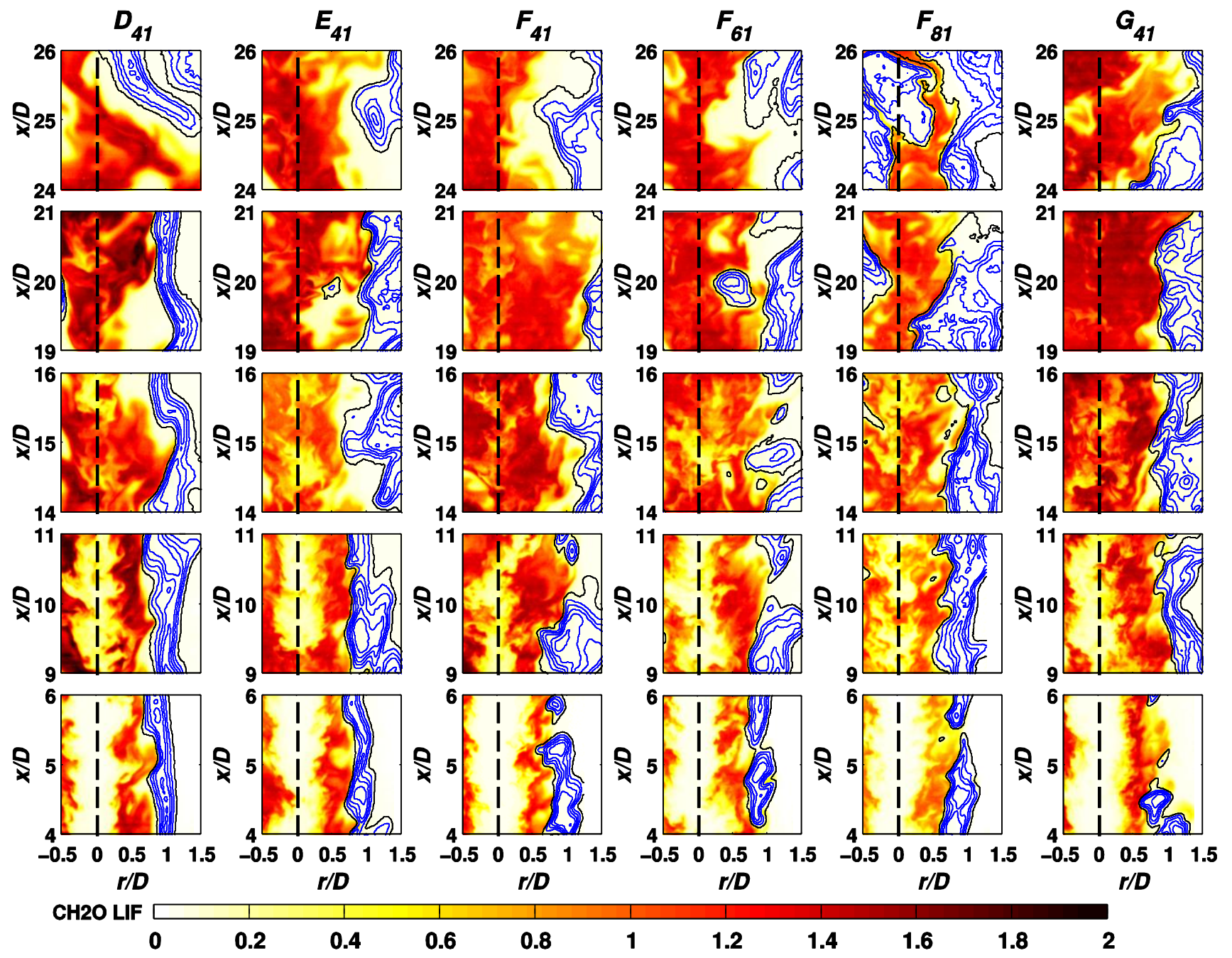


Figure 8 - Radial profiles of mean and RMS OH LIF (solid) and $\mathrm{CH}_{2} \mathrm{O}$ LIF (dashed) signals in flame $D_{41}$.
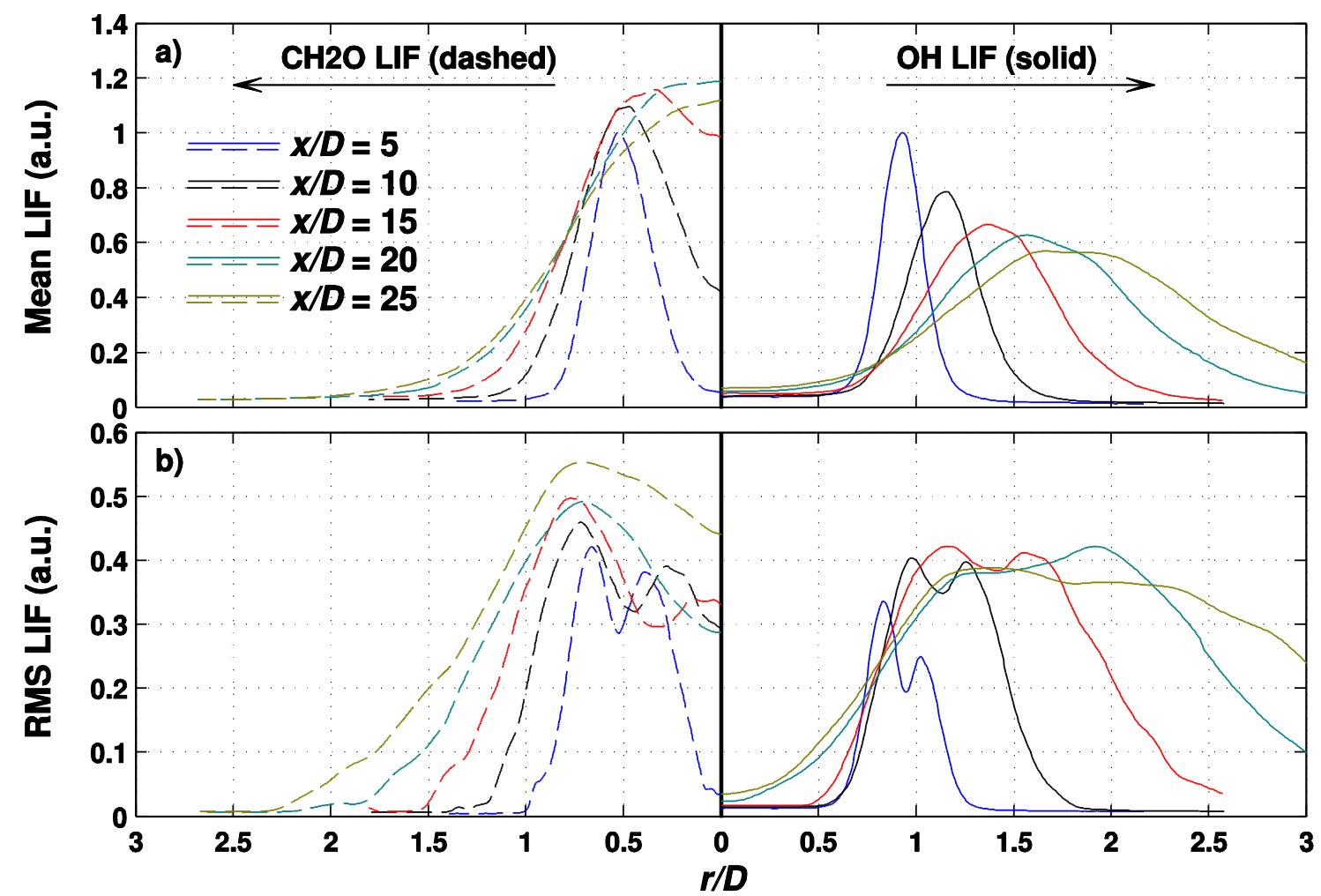
Figure 9 - Comparison of a) peak mean $\mathrm{OH}$ LIF signal, b) centerline mean $\mathrm{CH}_{2} \mathrm{O}$ LIF signal and c) radial position of peak mean LIF signals in all the turbulent flames.

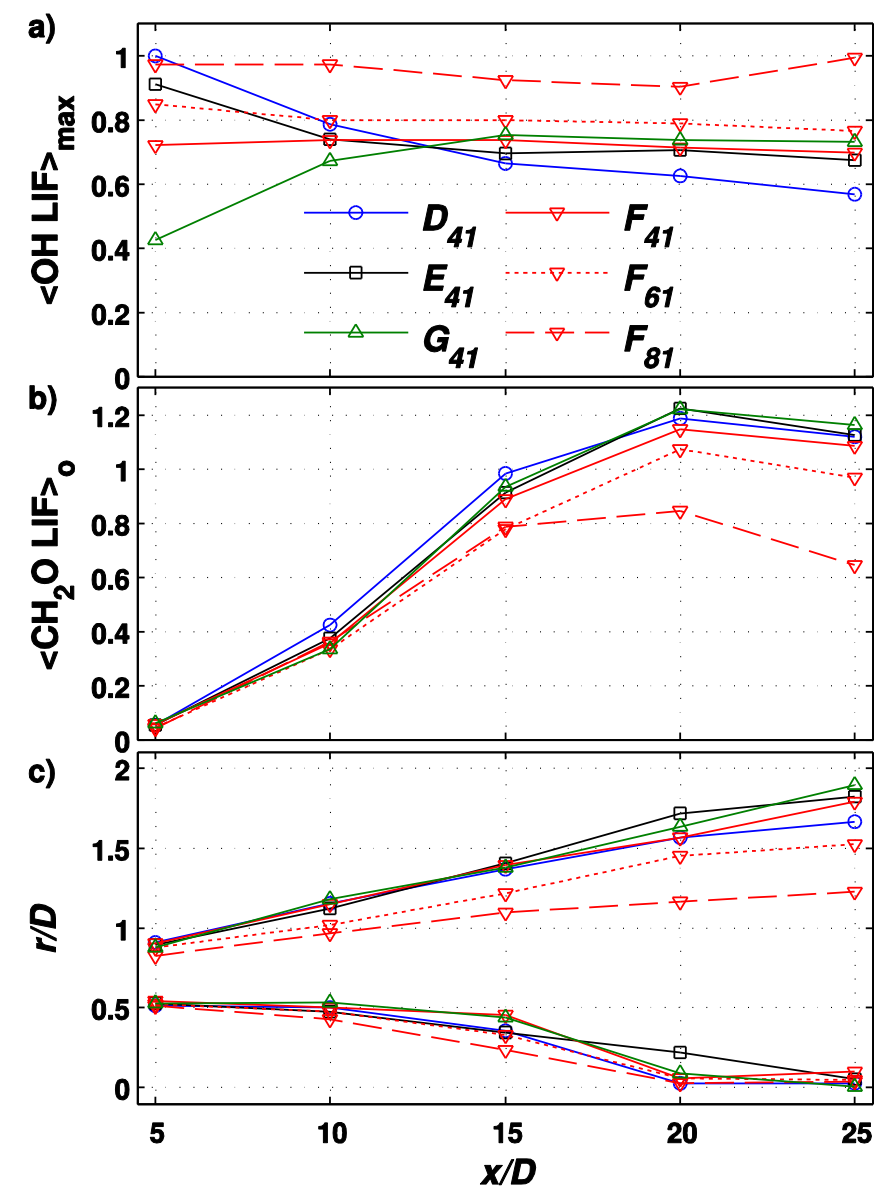


Figure 10 - Mean radial gradient of the axial velocity conditional on OH LIF iso-contours of 0.24 . Velocity gradients are normalized by $U_{b u l k} / R$ for each flame.
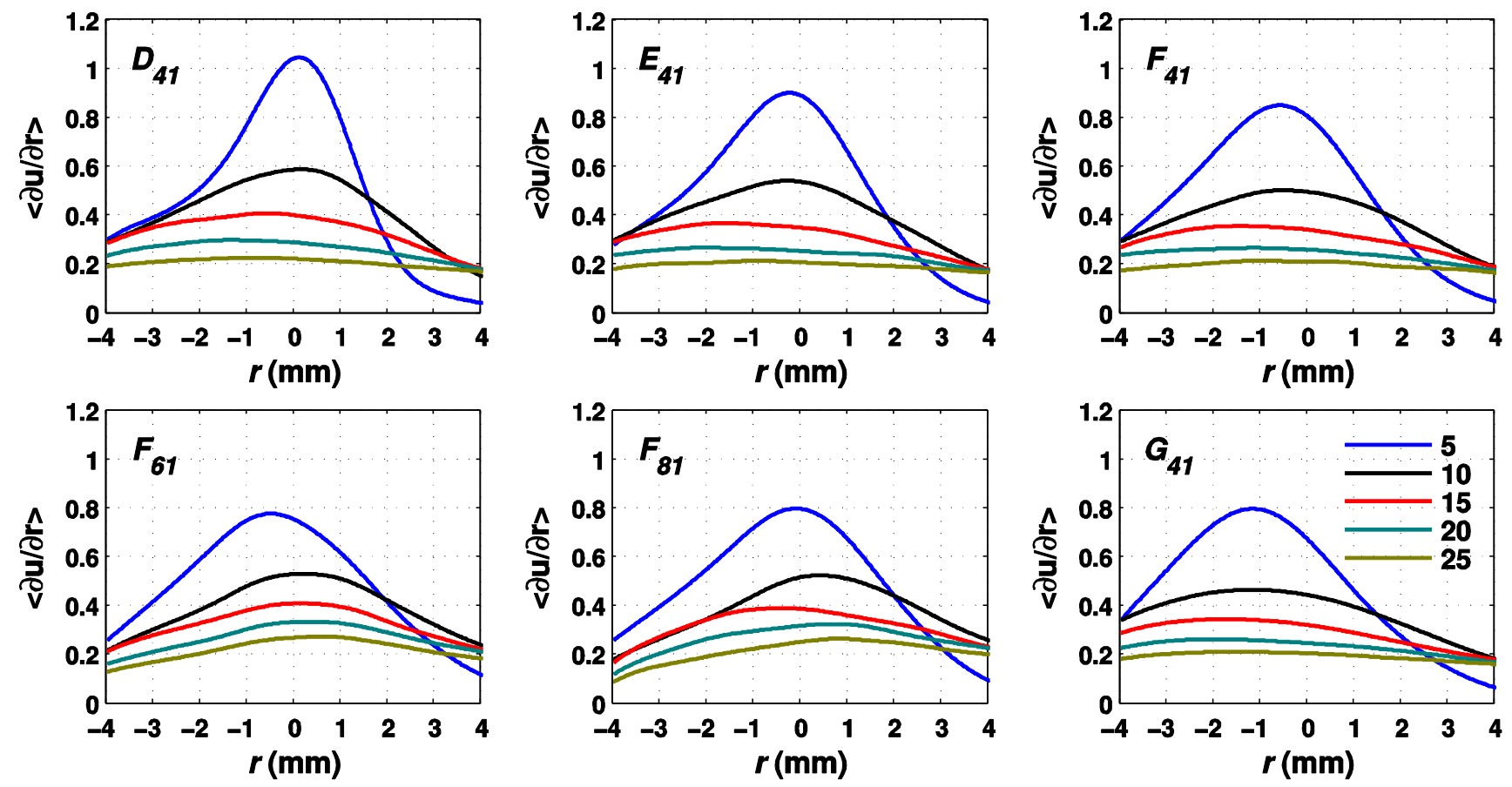
Figure 11 - Number of reaction zone holes per OH LIF snapshot in the turbulent flames.
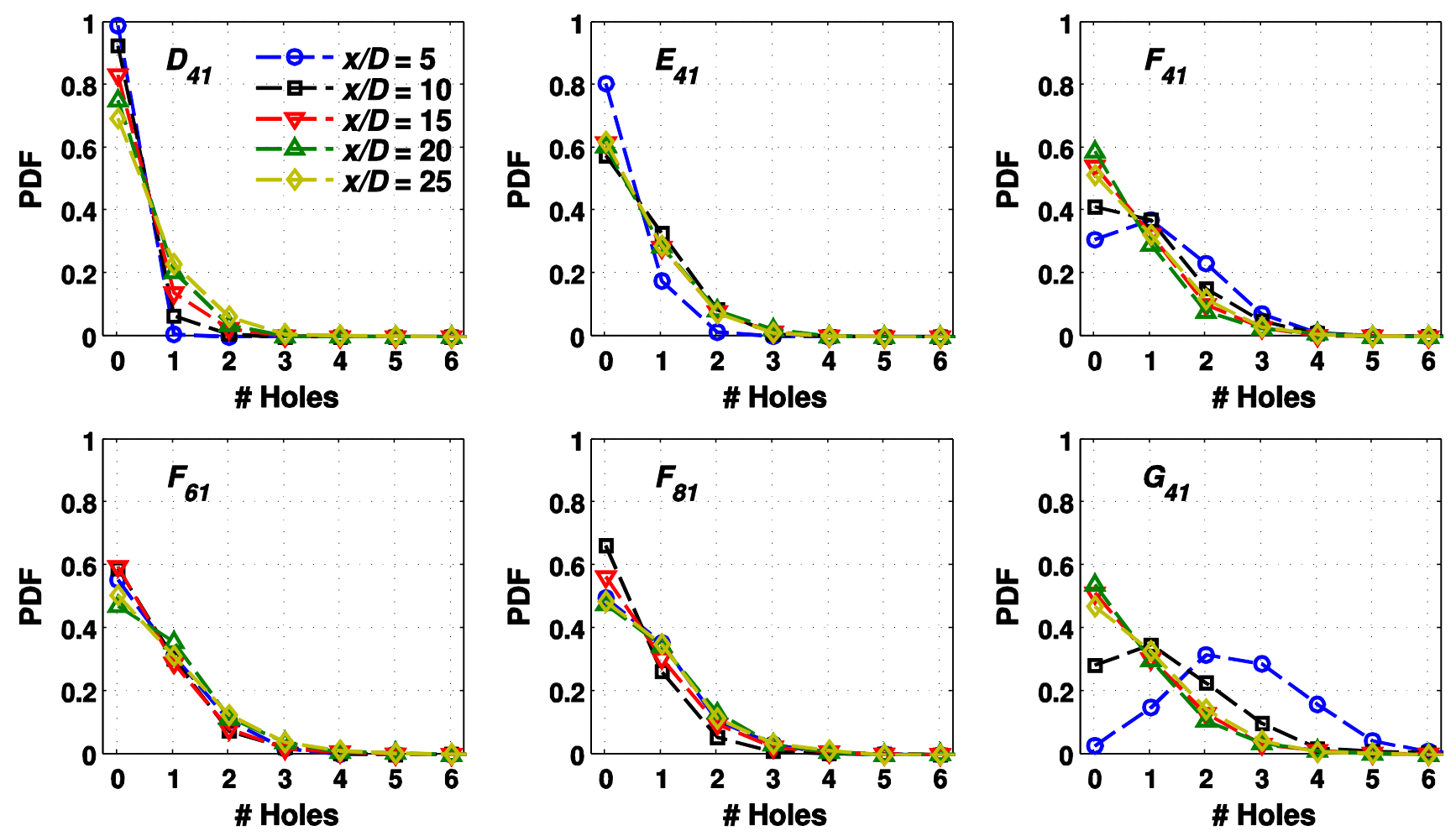
Figure 12 - PDFs of the spacing between the $\mathrm{CH}_{2} \mathrm{O}$ and $\mathrm{OH}$ LIF layers in the turbulent flames. Negative values indicate that the layers are overlapping.
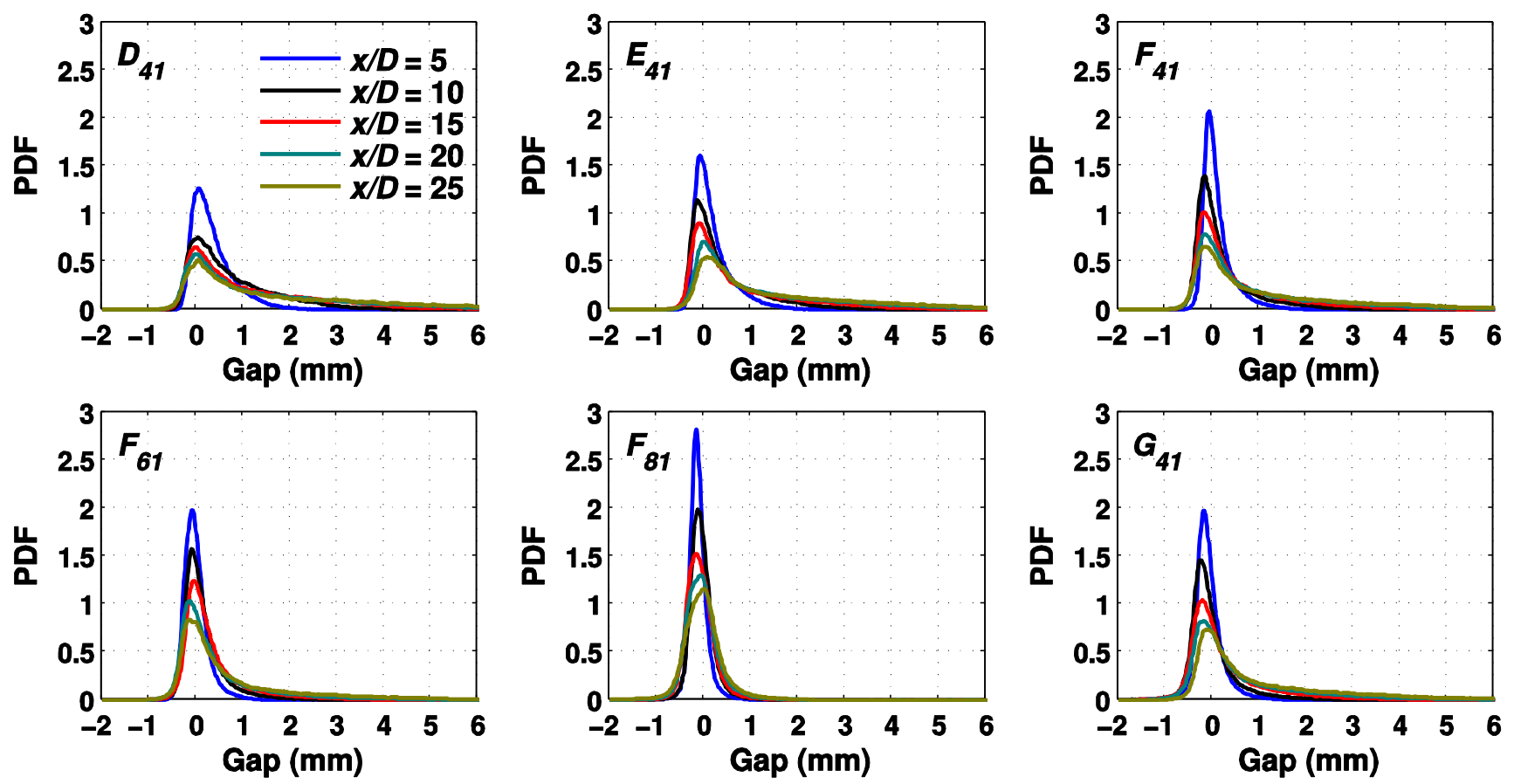